MOTIVATION AND SELF-REGULATION

Axel Grund 
Published online by Bielefeld University (2019):

URL https://pub.uni-bielefeld.de/record/2939237 (doi: https://doi.org/10.4119/unibi/2939237)

URN urn:nbn:de:0070-pub-29392376 (http://nbn-resolving.de/urn:nbn:de:0070-pub-29392376)

This is an open-access work distributed under the terms of the Creative Commons Attribution License (CC BY-SA 4.0). The use, distribution, or reproduction in other forums is permitted, provided the original author or licensor are credited and that the original publication is cited, in accordance with accepted academic practice. No use, distribution, or reproduction is permitted without compliance with these terms:

License deed https://creativecommons.org/licenses/by-sa/4.0/deed.de

Legal code https://creativecommons.org/licenses/by-sa/4.0/legalcode.de 


\title{
MOTIVATION AND SELF-REGULATION
}

\author{
Cumulative habilitation \\ presented by Dr. Axel Grund, \\ born, July, 27th 1979 in Gießen.
}

Bielefeld, in November 2018

Dean: $\quad$ Prof. ‘in Dr. Johanna Kißler

Reviewer: $\quad$ Prof. Dr. Stefan Fries

Prof.'in Dr. Elke Wild

Prof. Dr. Dr. h.c. Detlev Leutner

Bielefeld University

Department of Psychology and Sports Science

Published online in November 2019 


\section{CONTENTS}

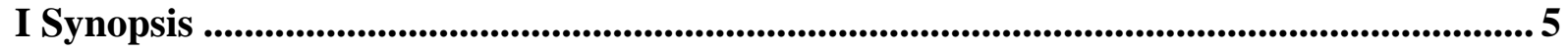

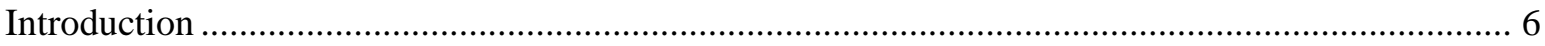

Chapter 1. Competing Actions as a Specific Challenge for Experience and Performance .................. 8

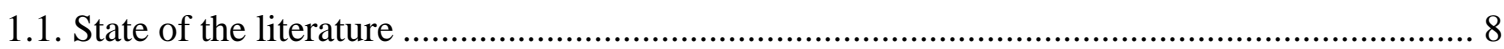

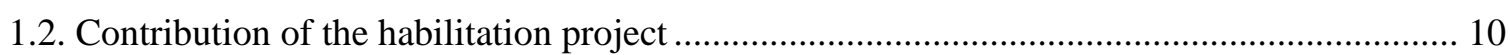

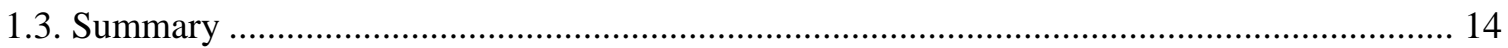

Chapter 2. Self-Control: Overcoming Inner Hindrances, or Business Before Pleasure? ................... 15

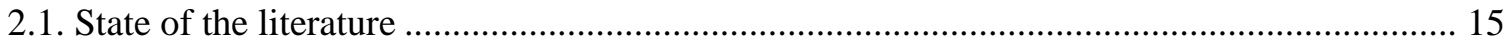

2.2. Contribution of the habilitation project .............................................................................. 18

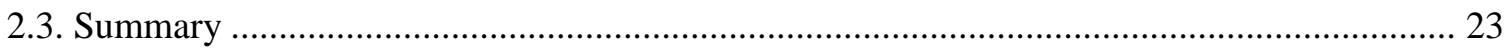

Chapter 3. Mindfulness: Self-Regulation as Insight and Emotional Non-Reactivity........................ 24

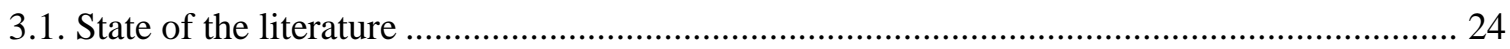

3.2. Contribution of the habilitation project ................................................................................. 26

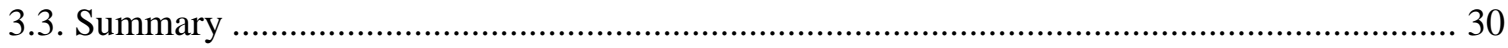

Chapter 4. Self-Regulation as Self-Congruent Goal Selection......................................................... 31

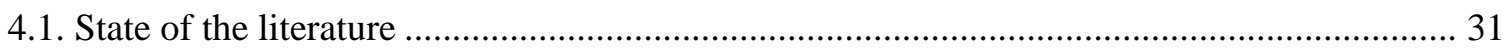

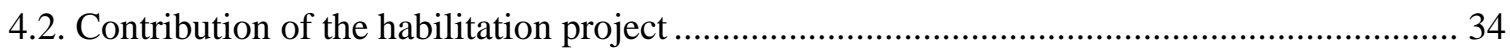

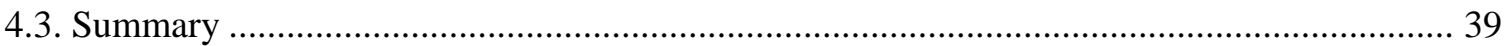

Chapter 5. Self-Regulation as Acquisition and Application of Meta Knowledge............................. 41

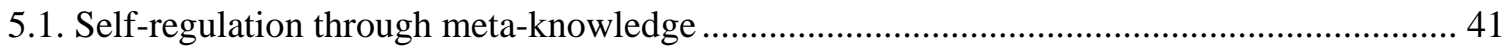

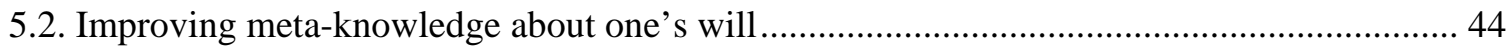

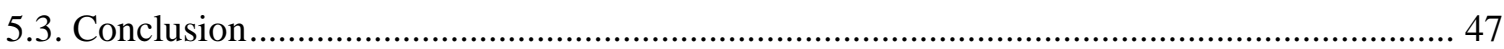

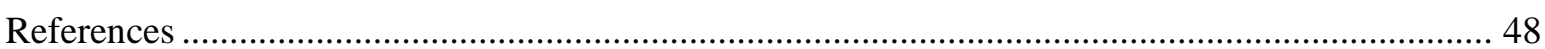

II Appendix: Publications of the habilitation project .........................................................6 61

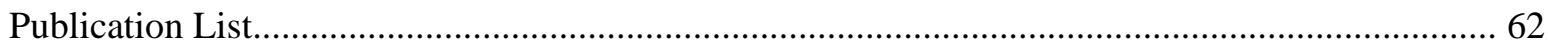


I Synopsis 


\section{Introduction}

Besides adequate motivation (e.g., intrinsic motivation, self-concept), and general (e.g., intelligence) and task-specific (e.g., previous knowledge) capabilities, students' academic achievement is often also explained by self-regulatory capabilities (e.g., Duckworth \& Seligman, 2005). In educational psychology, the notion of self-regulation typically refers to metacognitive processes and strategies that regard the monitoring and regulation of learning behavior, and that enable students to reach their academic goals (Pintrich, 2000; Schunk, 2001; Zimmerman, 2000). The aim of the present habilitation project is to further this understanding of self-regulation. I, together with my colleagues, conducted several studies to corroborate the following arguments.

First, in order to understand why students succeed or fail in academic contexts, it is important to view their academic endeavors in relation to their non-academic strivings (cf., Boekaerts \& Niemivirta, 2000). Obviously, there is more that is important for most individuals besides academic achievement, which renders self-regulation to be a much more complex task than mere task persistence. For example, students need to also maintain self-integrity in order to live a happy and satisfied life (Kuhl \& Fuhrmann, 1998; Sheldon, 2014).

Second, in terms of psychological well-being, it is therefore important to have a larger view of the daily balance between one's academic duties and one's private life (e.g., family, leisure time) than the view obtained from only a "studying” perspective. As educational psychologists, it may be tempting to see all leisure-related behavior as a potential distraction from students' academic assignments (e.g., Bembenutty \& Karabenick, 2004). In the present project, I take a more universal perspective of self-regulation, and try to show that the opposite conflict-that is, academic tasks interfering with one's private life-may be equal, or even more critical, to an individual's well-being. Similarly, because I assume general principles and effects underlying the targeted phenomena and concepts, I try to show that conflicts between multiple motivational tendencies and life domains are not only an issue for students, but for teachers as well.

Third, I think it is of critical importance to review the targeted phenomena and concepts associated with self-regulation in academic contexts from an in-depth motivational perspective. This is important for two reasons: a) because motivational and self-regulatory concepts claim the same explanatory space (e.g., persistence), motivational variables may serve as confounding variables for self-regulatory "capabilities". For example, before we can infer that students are not able, or fail, to persist in studying, despite a current leisure temptation, we need to ensure that they indeed wanted to persist. b) The acknowledgement of general motivational variables, such as value orientations, may also help to uncover certain implicit normative assumptions about the "right" way of living, which I see embedded in research on the phenomena and concepts related to self-regulation.

Forth, the latter point is especially true for the concept of self-control strength and its infamous counterpart, (academic) procrastination. I try to show that both concepts become more understandable and less enigmatic when motivational variables that regard the energetization of behavior are acknowledged, in addition to those variables that regard the direction of behavior. 
Fifth, I think that the concept of mindfulness offers a fresh and promising perspective of the abovementioned issues. I try to show that mindfulness, compared to self-control, seems to enable flexible self-regulation based on self-insight and self-determined behavior, thereby supporting a balance between one's academic and leisure engagements. I also try to show that mindfulness, as a specific quality of awareness (i.e., present-oriented and non-judgmental), may promote the development of situational interest in academic settings.

Finally, the concept of mindfulness highlights the pressing need to acknowledge processes of goal selection and self-integrity in contemporary models of self-regulation that mostly focus on processes of goal maintenance and goal achievement. This way, the integrative role of mindfulness in helping to align energetic and directive motivational processes is also emphasized.

The present synopsis is organized into five chapters. In Chapters 1-4, I elaborate on the arguments just sketched. In each of these chapters, I first outline the current state of the literature relevant to the problem I address. I then describe how the different studies of my habilitation project contribute to this literature. Each of these chapters ends with a concluding summary. In Chapter 5, building on these arguments, I argue for an integrative model of self-regulation that focuses on meta awareness and intrapsychic insight.

In Chapter 1, I elaborate on the case of competing action tendencies as a specific challenge for selfregulation and well-being.

In Chapter 2, I introduce and scrutinize the concept of self-control in terms of its relevance to dealing with competing action tendencies, and in terms of the (motivational) processes that underlie the impressive effects associated with self-control.

In Chapter 3, I make recourse to the concept of mindfulness as a possible alternative way (compared to self-control) of dealing with competing acting tendencies in general, and study-leisure conflicts specifically. In addition, I analyze the specific role of mindfulness to promote a functional learning state in terms of situational interest.

In Chapter 4, I present research that integrates the aforementioned findings and arguments by highlighting the role of self-congruent goal selection for positive experiences and sustained behavior, and by discussing capabilities and strategies that may promote these (self-regulatory) processes.

Finally, in Chapter 5, my synopsis ends with the presentation of an integrative model that refers to self-regulation as the acquisition and application of meta knowledge about one's motivational processes (and capabilities), and I propose directions for future research in line with this reasoning. 


\section{Chapter 1. Competing Actions as a Specific Challenge for Experience and Performance}

\subsection{State of the literature}

Motivational variables are central to explaining experiences and behavior. In educational psychology, motivation typically refers to the values underlying, and the motivational beliefs attributed to, a specific learning task, or to learning (contexts) more generally (Covington, 2000; Eccles \& Wigfield, 2002; Wentzel \& Miele, 2016). Drawing on motivational interference theory (e.g., Fries \& Dietz, 2007; Fries, Dietz, \& Schmid, 2008), the present research assumes that knowledge about these learning-related motivational tendencies is not enough to explain why students have difficulties achieving their learning goals, and why some students may face more such difficulties than others. Rather, learning motivation—as any another motivational tendency — needs to be considered in relation to potentially rivaling action tendencies inside the individual. Indeed, in everyday life, the typical question students face is not whether they engage in studying or not, but whether they engage in studying or do something else. Specifically, a decision for studying is often simultaneously a decision against other valuable action alternatives. Different from other ideas (e.g., Heckhausen \& Gollwitzer, 1987), motivational interference theory claims that with the decision for a certain action alternative, the energetic power of available, but currently dismissed, action opportunities remains an influential force. The more important the dismissed alternative, the more impairments should be experienced while being engaged in the "focal" activity. For example, students report a worsened mood, higher distractibility, and lower persistence while studying under the presence of an attractive leisure-related alternative (Fries \& Dietz, 2007; Schmid, Hofer, Dietz, Reinders, \& Fries, 2005).

Previous research in this field showed that such motivational interference effects can explain postdecisional impairments in ongoing goal pursuit beyond the motivational characteristics ascribed to this goal, for example, in terms of intrinsic and extrinsic incentives (Fries et al., 2008; Grund \& Fries, 2012). Specifically, whereas the motivational quality of the central studying activity (e.g., relation between intrinsic and extrinsic incentives) seems crucial to explaining how concentrated students are during studying, the motivational quantity of the dismissed alternative (opportunity costs; i.e., the overall amount of incentives that could not be realized, cf., Eccles \& Wigfield, 1995; Flake, Barron, Hulleman, McCoach, \& Welsh, 2015) seems of additional informative value (Grund, 2013).

Hofer et al. (2007) further proposed that living in post-industrialized countries may amplify such motivational interference effects. Drawing on Inglehart's idea of value change (1997), Hofer et al. identified the competition of achievement- and well-being-oriented values to be crucial for understanding students' difficulties in self-regulated learning. Given the rise of post-modern well-being-oriented values that complement formerly predominant modern achievement values, today's students may feel frequently torn between equally highly valued action opportunities (e.g., studying vs. meeting friends). This seems to be the case especially when both achievement values and well-being values are held preeminently (Fries, Schmid, Dietz, \& Hofer, 2005). In addition, higher achievement value orientations (and lower well-being value orientations) were consistently found to be related to lower post-decisional impairments when studying was confronted with a leisure-related alternative (e.g., better mood and lower distractibility), whereas the opposite 
was true for post-decisional impairments during leisure time (e.g., Fries et al., 2005; Kilian, Hofer, Fries, \& Kuhnle, 2010; Kilian, Hofer, \& Kuhnle, 2010).

Previous studies also highlighted that both typical conflict constellations - that is, studying that is interfered with by a leisure-related alternative, and leisure time that is interfered with by a study-related alternative-are crucial for students psychological functioning (Grund, Brassler, \& Fries, 2014). The typical case in educational psychology is to think about how students' learning experience and behavior can be explained and improved. From this perspective, all other motivations (e.g., social media) constitute distractions or temptations that need to be overcome in favor of academic goal pursuit (cf., Bembenutty \& Karabenick, 2004). In line with this reasoning, lower post-decisional conflict experiences during studies were predictive for grades and academic time investment (Hofer et al., 2007; Hofer, Kuhnle, Kilian, Marta, \& Fries, 2011). However, from a broader perspective, it is obvious that leisure-related and social activities are also crucial for personality development (Hofer, Kuhnle, \& Kilian, 2014). For example, as theorized by Hofer (2010), individual exploration during leisure time, in relation to the requirements and guidelines of formal learning settings, constitutes an important opportunity for the development of personal interests. Hence, adequate leisure experiences are important not only in terms of hedonic well-being — with a focus on pleasure attainment and recreation - but also in terms of eudaimonic well-being — with a focus on self-realization (Ryan \& Deci, 2001; Ryff, 1989). In this sense, it is important to note that post-decisional impairments during leisure time due to study-related activities were predictive of social adaptation and study strain (Grund et al., 2014). More generally, there is ample evidence that intrapsychic conflict due to competing motivations is generally detrimental for well-being (e.g., Boudreaux \& Ozer, 2013; Emmons \& King, 1988; Gray, Ozer, \& Rosenthal, 2017; Riediger, 2007; Riediger \& Freund, 2004).

Despite this rich body of literature, some open questions remain. With respect to research on motivational interference, the phenomenon has been analyzed with qualitative data (Schmid et al., 2005), in experimental designs (Fries \& Dietz, 2007; Fries \& Schmid, 2007), and with hypothetical (Fries et al., 2008; Grund \& Fries, 2012) and idiographic conflict situations (Grund et al., 2014), but not in real time or in everyday life. In addition, the typical target group has been school and university students, implying that motivational interference effects may be especially relevant for individuals who have not (yet) developed adequate self-regulation capabilities. Accordingly, the focus has been on specific outcome variables that may depend on the intensity of study-leisure conflict experiences, such as academic and leisure functioning. In work psychology, however, the related concept of work-family conflict is also applied to individuals who are more experienced, and to a broader set of outcome variables, such as general well-being, work satisfaction, and relationship satisfaction (Amstad, Meier, Fasel, Elfering, \& Semmer, 2011; Greenhaus \& Beutell, 1985; Katz \& Kahn, 1978; Mesmer-Magnus \& Viswesvaran, 2005; Netemeyer, Boles, \& McMurrian, 1996, Nohe \& Sonntag, 2014). Finally, it remains an open question as to how the concept of motivational interference relates to other concepts of motivational (e.g., goal) conflict. I, together with my colleagues, conducted three studies to address these gaps in the literature: an experience-sampling study to enlarge the ecological validity of the motivational interference idea, a cross-sectional study among teachers to demonstrate its generalizability to different populations and outcome measures, and a theoretical review to integrate the idea of motivational interference in other conceptions of motivational conflict. 


\subsection{Contribution of the habilitation project}

\subsubsection{Studying against your will: Motivational interference in action (Grund, Schmid, \& Fries, 2015)}

The major goal of this study was to verify the idea of motivational interferences in everyday life and real time. More specifically, we were interested in the prevalence of situations of motivational conflict during studying - that is, situations where students were engaged in studying, but simultaneously had other motivational tendencies activated. We were also interested in the consequences of such conflict situations in terms of motivational interference - that is, impairments during ongoing goal pursuit.

Drawing on Riediger and Freund (2008), we distinguished between two types of conflict experiences. Want conflicts refer to situations where the feeling emerges that one would like to do something else rather than what one is currently doing. By contrast, should conflicts refer to situations where the feeling emerges that one should be doing something else rather than what one is currently doing. We reasoned that want conflicts should be especially prevalent during studying (cf., Grund et al., 2014). We also reasoned that situations of motivational (want) conflict during studying are accompanied by worse mood, compared to “unconflicted” studying. Finally, mirroring findings from Grund et al. (2014), we hypothesized that a high average conflict intensity during studying should be specifically related to worse academic functioning, but not to worse social functioning.

To test these assumptions, we set up an experience-sampling study during an intensive studying phase (i.e., at the end of the semester). Six times per day over one week, participants ( $N=58$ university students, 69\% female) provided answers on want and should conflict experiences, as well as on their momentary affective well-being (cf., Schallberger, 2005). In order to assess students' general academic functioning, we applied measures of academic adaptation (Baker \& Siryk, 1999), study satisfaction (Westermann, Heise, Spies, \& Trautwein, 1996), and self-reported relative performance after the experience sampling period. In addition, we assessed their social adaptation (Baker \& Siryk, 1999).

Our findings revealed that motivational conflicts, especially want conflicts, were indeed a common experience during studying. In 424 (63.1\%) out of the 672 study-related occasions, students reported that they wanted to do something else rather than their current academic activity. These "desires” referred most often to leisure-related activities (73.4\%). Multilevel analyses also showed that compared to "unconflicted" studying, studying under the presence of a valued leisure-related activity went along with lower positive activation, lower valence, and higher negative activation, whereas these motivational interference effects seemed strongest for positive activation. As expected, we also found that students who reported, on average, more intensive conflicts during studying also reported worse academic adaptation, less study satisfaction, and worse performance. As expected, we found no relationship between the average conflict intensity during studying and participants' social adaptation.

Taken together, these findings show that motivational conflicts during studying depict the rule rather than the exception. They also support the claim that such conflicts are accompanied by affective impairments in the short run, and potentially lead to long-term domain-specific malfunctioning. These causal interpretations, however, need to be taken with caution. It could also be that students' general study 
satisfaction and their momentarily worse mood influenced their daily conflict experiences, and not the other way around.

\subsubsection{The long arm of work: A motivational conflict perspective on teacher strain (Grund, Brassler, \& Fries,} 2016)

With this study, we wanted to enlarge the scope of validity for motivational interference theory. Our basic idea was that the concept of motivational interference may help to explain phenomena of work-family conflict in relation to teacher strain. Specifically, we assumed that acknowledging the multiple demands and motivations that teachers have to deal with across several life domains better fits with the inherent complexity of today's challenges and potential stressors, rather than assuming the sources of teachers' emotional strain solely root within the work domain. Our central argument was that adequate leisure experiences are crucial for preventing emotional exhaustion. Drawing on effort-recovery theory (Meijman \& Mulder, 1998), we concluded that especially work-to-family conflict (WFC)—defined and operationalized as the negative impact that demands from the working domain have on teachers' private lives (Frone et al., 1992)—relates to their emotional exhaustion. Moreover, we concluded that motivational interference effects in the leisure domain due to work-related action tendencies convey this effect. The idea behind these assumptions was that WFC impedes recovery from work because teachers cannot detach themselves psychologically during their free time due to motivational interference effects. Emphasizing the power of the situation, we furthermore sought to demonstrate the independence of these conflict experiences by controlling teachers' general selfregulation capability, as an individual difference variable.

We tested these assumptions in a cross-sectional study among teachers ( $N=234,72 \%$ female) from different types of schools in North Rhine-Westphalia, Lower Saxony, and Hesse in Germany. We asked them to fill out measures of work-to-family conflict (WFC) and family-to-work conflict (FWC, Netemeyer et al., 1996), emotional exhaustion (Enzmann \& Kleiber, 1989; Hagemann \& Geuenich, 2009), and self-regulation capabilities (Luszczynska, Diehl, Gutiérrez-Dona, Kuusinen, \& Schwarzer, 2004). In addition, we adapted the typical procedure to capture motivational interference effects among students (e.g., Fries et al., 2008; Grund \& Fries, 2012) to match the situation of teachers. Specifically, we confronted teachers in our sample with two conflict scenarios. In the first scenario (i.e., experience of motivational interference during work, MIW), they were asked to put themselves in a situation where they are sitting at home in the afternoon at their desk, planning a lesson for the next day. Then, a friend calls and asks whether they would like to meet up. In the second scenario (i.e., experience of motivational interference during leisure time, MIL), participants were asked to put themselves in a situation where they were sitting together with friends at home in the afternoon, enjoying their leisure time. Then, a colleague calls and asks for help concerning a professional question. After each scenario, participants were asked about their post-decisional impairments in mood, persistence, and cognitive functioning, given the decision to stick to their initial activity, thereby dismissing the conflicting alternative.

Findings were in line with the assumptions of recovery theory in that WFC, but not FWC, was a critical predictor of teachers' emotional exhaustion in multiple regression analyses, yielding a large effect. Findings also confirmed that this effect was partially mediated mainly via higher post-decisional impairments 
during leisure time (MIL) in the specific conflict scenarios. Hence, motivational interference may indeed denote a mechanism by which recovery is hindered and emotional exhaustion is boosted. Remarkably, acknowledging teachers' general self-regulation capabilities as a control in the regression models did not change these findings much. Hence, although teachers with better self-regulation reported less emotional exhaustion, this could not (or only to a small extent) remedy the grueling effect of work-to-family conflicts.

Taken together, these findings speak to the importance of conflicting action tendencies, not only for students, but also for teachers, and not only with regard to academic outcomes, but also for psychological well-being in a broader sense. Again, causal inferences are not warranted, although they are in line with previous experimental research on the effects of motivational interferences in academic contexts (e.g., Fries \& Schmid, 2007). Despite this important limitation, we can learn from these findings that concepts of selfregulation that mainly focus on goal maintenance in achievement contexts ("stay focused", "get things done”; e.g., Baumeister \& Heatherton, 1996; Hofmann, Luhmann, Fisher, Vohs, \& Baumeister, 2014; Luszczynska et al., 2004; Tangney, Baumeister, \& Boone, 2004, see also Chapter 2) seem to have little additional explanatory value above the idea of intrapsychic conflict. This is not surprising, given that they do not acknowledge a certain balance between different aspects of life, such as tension and relaxation, or hard work and faineance. However, such a balance seems to be crucial for preventing prolonged emotional exhaustion (Philipp \& Kunter, 2013). I take up this idea in Chapter 3 when introducing the concept of mindfulness as a fresh perspective to self-regulation and motivational conflicts.

1.2.3. Aiming at a moving target: Theoretical and methodological considerations in the study of intraindividual goal conflict between personal goals (Gorges \& Grund, 2017)

In this contribution, we tried to place the idea of motivational interference theoretically into context. We aimed at identifying and reconciling major perspectives of research on motivational conflict by applying two perspectives: a structure-like perspective that focuses on relationships between goals and their connection to central aspects of the self, and a process-like perspective that focuses on different action phases, from intention formation to goal disengagement.

In this regard, we used the concept of motivational interference to illustrate that motivational (goal) conflict not only refers to a cognitive construct (i.e., individuals' mental representations of conflicting goals), and is not necessarily solved with the decision for a specific goal pursuit (cf., Heckhausen \& Gollwitzer, 1987; Shah \& Kruglanski, 2002). Rather, motivational conflict also manifests itself in a concrete experiential instance during goal pursuit (i.e., whether an individual experiences intrapsychic conflict due to competing action alternatives). Hence, the idea of motivational interference highlights that the negative effects of goal conflicts, in terms of impairment well-being and performance, are likely rooted in this specific level of action. Whereas an individual may generally think that family and work go together well, this same individual may experience critical opportunity costs in either life domain, depending on the concrete daily decisions and affordances. Hence, when researchers are interested in the (negative) consequences of motivational conflict, it seems critical to apply such a process-like perspective to goal pursuit.

With regard to the structure-like perspective, however, a potential blind spot of motivational interference theory also becomes apparent. The theory rests on the basic assumption that impairments in 
ongoing experience and behavior are due to the motivational characteristics of the conflicting alternative (e.g., Fries et al., 2008). From our findings, however, it is also clear that the motivational characteristics of the focal activity are also crucial. Specifically, as described in Section 1.1, besides opportunity costs stemming from a neglected action alternative, the motivational quality of the central activity seems crucial to explaining ongoing experience and behavior. For example, the more intrinsic incentives were attached to studying, the less distractibility students reported when studying was interfered with by a leisure-related alternative (Grund \& Fries, 2012; Grund, 2013; Grund et al., 2014). Both effects seem crucial. However, their relation is not regarded in motivational interference theory. For example, it seems reasonable that motivational interference effects are especially likely when the initial motivation for the "focal" activity is suboptimal, for example, in terms of self-determination, or in terms of expectancy parameters. Individuals may orient themselves more to alternative actions when current engagement is at odds with deeper personality structures, such as basic values, needs, and motives (Deci \& Ryan, 2000; Sheldon, 2014; Rheinberg \& Engeser, 2012). Hence, applying a structure-like perspective to motivational conflict may eventually show that the true problem of difficulties in ongoing self-regulation may not lie in situations of conflict between different action alternatives, but in intrapsychic ambivalence regarding a specific goal. 


\subsection{Summary}

The notion of competing motivational tendencies, as implied in the concept of motivational interference, seems relevant because it depicts a common everyday phenomenon among students, and because it goes along with serious drawbacks in experience and performance in different life domains and in different phases of life. Hence, it is informative to not only better understand students learning (mis-) behavior, but also to understand difficulties in experience and performance in a broader sense. To gain a complete picture, however, it seems critical to combine these ideas with more basic principles of motivation building and goal selection. In addition, I realized that it is necessary to think in more detail about what self-regulation actually means, and how self-regulation works. Is it regulation of the self, or by the self (cf., Kuhl, 1996)? And, what is the self?

In the next chapters of this habilitation project, I try to provide answers to some of these questions. I scrutinize and compare two timely and glitzy concepts that may be helpful in this regard: Self-control and mindfulness. I also take a more global perspective of phenomena associated with self-regulation (e.g., procrastination) by asking how different self-regulation is (or can be) from motivation because both lines of research seem to claim a similar scope of validity. 


\section{Chapter 2. Self-Control: Overcoming Inner Hindrances, or Business Before Pleasure?}

\subsection{State of the literature}

Considerations of self-control have a long tradition, and at the same time, are extremely popular and timely. A recent Web of Science search revealed that publications on self-control have increased continuously in the social sciences since the early 19th century, with a peak in the last fifteen years (see Table 1). In addition, a Google search at the time of writing (November 2018) revealed 29,300,000 hits for the term self-control. Hence, the notion of self-control has been of public interest at least since the 1980s (perhaps, not least because of the famous pop song by Laura Branigan in 1984). Self-control, colloquially also known as willpower, is a highly appreciated concept in the psychological sciences, as well as in the public. Self-control, or rather the lack of it, is held responsible for a multitude of personal and societal problems, such as pathological gambling, obesity, substance abuse, criminality, impulsive buying, academic failure, procrastination, interpersonal aggression, and impaired psychological and physical well-being (e.g., Baumeister, \& Heatherton, 1996; de Ridder, Lensvelt-Mulders, Finkenauer, Stok, \& Baumeister, 2012).

Table 1: Web of Science Topic Search on the Key Terms "Self-Control" and "Mindfulness" Depending on the Time of Publication

\begin{tabular}{lll}
\hline $\begin{array}{l}\text { Web of Science search } \\
\text { (November 2018) }\end{array}$ & “self-control” hits & “mindfulness” hits \\
\hline $1900-1930$ & 3 & 0 \\
$1931-1960$ & 7 & 0 \\
$1961-1980$ & 378 & 3 \\
$1981-1990$ & 380 & 18 \\
$1991-2000$ & 1,230 & 102 \\
$2001-2010$ & 2,737 & 1,403 \\
$2011-2018$ & 6,970 & 9,122 \\
\hline Total & 11,708 & 10,652 \\
\hline
\end{tabular}

What is exactly meant by self-control, and why is self-control important for the self-regulatory challenge of competing motivations and a good life in general? When I started to occupy myself with the notion of self-control, I quickly realized that answers to these questions are much more complex and nebulous than may appear at first glance. This ambiguity, together with the popularity of the concept, makes selfcontrol both an especially interesting and pressing topic to study.

My analysis centers on the concept of self-control as introduced by Roy Baumeister and his colleagues (e.g., Baumeister \& Heatherton, 1996; Baumeister, Heatherton, \& Tice (1994) because it dominates the scientific discussion, and stimulated a multitude of (critical) research (cf., Carter, Kofler, Forster, \& McCullough, 2015; de Ridder, Lensvelt-Mulders, Finkenauer, Stok, \& Baumeister, 2012; Hagger, 
Wood, Stiff, \& Chatzisarantis, 2010; Inzlicht \& Schmeichel, 2012; Saunders, Milyavskaya, Etz, Randles, \& Inzlicht, 2018). Tangney, Baumeister, and Boone (2004) define self-control as a person’s “ability to override or change one's inner responses, as well as to interrupt undesired behavioral tendencies and refrain from acting on them" (p. 275). Other contributions highlight self-control as the capability to pursue long-term goals despite momentarily affective "temptations” (Fishbach \& Shah, 2006; Hofmann et al., 2014). Several points are remarkable in these definitions. First, self-control is seen as a capability or skill that distinguishes individuals and determines their well-being and success in life (Tangney et al., 2004). Second, it is a skill that unfolds its potential in post-decisional (i.e., volitional) action phases, when goals have been set and need to be implemented and maintained (cf., Heckhausen \& Gollwitzer, 1987). Third, self-control refers to overcoming inner resistances, referring to motivational problems (i.e., opposing impulses or aversion), in contrast to outer resistances, referring to capability problems (i.e., lack of learning strategies or prior knowledge, cf., Sokolowski, 1997). Finally, the process by which goal achievement is maintained is effortful inhibition.

With regard to the later aspect, the concept of self-control received especially wide attention in terms of the so-called ego-depletion effect, and with the metaphor of self-control strength as a limited willpower source or strength that quickly depletes when applied (e.g., Baumeister \& Heatherton, 1996; Muraven, Tice, \& Baumeister, 1998); like a muscle that becomes exhausted after exercise. Because self-control is effortful and psychologically costly, initial attempts to "control" oneself should result in a reduced resource, and eventually in reduced performance in a subsequent task that requires self-control. For example, after the selfregulation (or not) of an emotional response to an upsetting movie, physical stamina (squeezing a handgrip) was found to be reduced for those participants who were initially instructed to alter their emotional response (Muraven et al., 1998).

Recently, this capability, or skill interpretation, has been questioned both on conceptual (Inzlicht \& Schmeichel, 2012) and empirical grounds (Carter et al., 2015; Job, Dweck, \& Walton, 2010). In addition, the function of self-control via inhibition has been questioned (e.g., de Ridder \& Gillebaart, 2017; Saunders et al., 2018). Yet, despite these fundamental challenges, the idea of self-control remains popular. Rather, there have been attempts to enlarge the original concept of inhibitory self-control (de Ridder \& Gillebaart, 2017; Kotabe \& Hofmann, 2015), for example, by referring to situational strategies of self-control in the sense of the proactive and prospective regulation of exposure and opportunity to indulge in temptations (Duckworth, Gendler, \& Gross, 2016; Fujita, 2011). With these extensions, however, the concept of self-control becomes somewhat blurred, which makes it difficult to distinguish it from related, yet different, psychological phenomena.

I believe that the scientific community can learn most when we concentrate our critical analysis on the core idea of inhibitory self-control, which seems to make up what we may find most fascinating about the phenomenon. "Self-controlled" individuals seem to be able to not only master the challenges of the external (social) world, which may also be true for a general intellectual capability, such as intelligence, but additionally seem to be able to master their internal ambiguities and conflicts by actively quieting some parts of the ego (Duckworth \& Seligman, 2005), rendering self-control as a fundamental human capacity (Baumeister, Gailliot, DeWall, \& Oaten, 2006). Hence, self-controlled individuals are seen to have control 
I Synopsis: Chapter 2. Self-Control: Overcoming Inner Hindrances, or Business Before Pleasure?

over both the external and the internal world. In line with recent critiques in the field (e.g., Inzlicht \& Schmeichel, 2012), I wanted to scrutinize this understanding by a) taking a "motivational” perspective that acknowledges motivational variables as potentially confounding variables, by b) scrutinizing the idea of selfcontrol as a general mechanism of self-regulation that transcends different life domains, and by c) scrutinizing the function of self-control via inhibition. 


\subsection{Contribution of the habilitation project}

2.2.1. Study and leisure interference as mediators between students' self-control capacities and their domainspecific functioning and general well-being (Grund \& Fries, 2014)

This study followed an understanding of self-control as originally implied by Baumeister et al. (1994), as well as Tangney et al. (2004). Because self-control is seen to enable a post-decisional shielding of goals against conflicting action tendencies via inhibition, and because goal achievement should promote psychological functioning in various life domains (i.e., academic functioning, leisure functioning, and general well-being), we reasoned that interindividual differences in self-control should be related to a better psychological functioning via less indication of motivational interferences during studying and leisure time. We also expected domain-specific effects of motivational interferences during studying and leisure time with regard to the different indicators of psychological functioning (see Grund et al., 2016, Chapter 1).

Different to previous studies (e.g., Grund et al., 2014; Grund et al., 2016), we investigated these mediation hypotheses - not on the level of momentary motivational interference with respect to a specific action conflict, but rather-by asking participants ( $N=253$ university students, 55\% female) to identify the extent to which they generally experience impairments in mood and higher distractibility when their academic strivings become conflicted by leisure-related action tendencies, or the other way around (i.e., tendency for motivational interference during studying [TMIS] and leisure time [TMIL]). Interindividual differences in self-control were measured by the Self-Regulation Scale (Diehl, Semegon, \& Schwarzer, 2006), which reflects dispositional, post-decisional attention control, and emotion regulation in the face of difficulties of goal maintenance.

Findings largely supported the assumed indirect effect of self-control on psychological functioning via TMIS and TMIL, as well as the assumed context-dependent effect of TMIS and TMIL. For example, compared to TMIL, TMIS served as the stronger mediator between self-control and study satisfaction. By contrast, TMLI, but not TMIS, served as a mediator between self-control and leisure satisfaction, as well as social adaptation.

Aside from the typical problems associated with cross-sectional studies that are based on self-reports, it is worth mentioning that the negative relation between self-control and TMIS was large, whereas the negative relation between self-control and TMIL was small to medium in size. Similarly, the positive relation between self-control and the indicators of academic functioning was larger than the positive relation between self-control and the indicators of leisure functioning. Hence, mirroring findings from de Ridder et al. (2012), we found some indication for domain-specific effects of self-control, which seem to be especially pronounced with regard to academic functioning. These findings support the claim that self-control enables students to deal with competing motivations, which, in turn, may explain why they are both happy and successful. What remains open, however, is the question of why self-controlled individuals report lower impairments due to conflicting motivations. The classic interpretation, in line with the idea of inhibitory self-control, would be that individuals high (compared to low) in self-control initially experience the same amount of intrapsychic conflict when a study behavior is interfered with by a leisure alternative, but then are better able to "overcome" or "suppress" the upcoming leisure temptation in favor of the academic goal pursuit. In the next 
I Synopsis: Chapter 2. Self-Control: Overcoming Inner Hindrances, or Business Before Pleasure?

set of studies, I explicitly scrutinize this understanding by distinguishing between self-control in terms of an ability self-concept and self-control as effortful inhibition of inner resistances.

2.2.2. Self-control motivationally reconsidered: "Acting" self-controlled is different from "being good at" self-control (Grund \& Carstens, 2019)

This study was driven by a seeming contradiction implemented in the study of self-control. On the one hand, acting self-controlled should be psychologically costly, as mirrored in the notion of ego-depletion (e.g., Hagger et al., 2010; Muraven et al., 1998). On the other hand, the better one is self-controlled, the more successful and happier one reports being (de Ridder et al., 2012; Tangney et al., 2004). Intriguingly, Hofmann et al. (2014) found that individuals high (compared to low) in self-control not only find satisfaction when looking in hindsight at their moral style of living (which they call the "Puritan hypothesis" of self-control), but instead they found that interindividual differences in self-ascribed self-control also related positively to momentary positive affect in everyday life.

This begs the question: When individuals are typically happy with what they are doing, why would there be a need to exercise inhibitory self-control at all? As highlighted by Inzlicht, Bartholow, and Hirsh (2015), acts of self-control do presuppose an aversive intrapsychic conflict. Otherwise, self-control would be obsolete and motivational forces could explain what individuals do and how persistent they are in what they are doing (see also Sokolowski, 1997 and Chapter 4). We figured that this might have something to do with the typical measure applied to capture interindividual differences in self-control: the Self-Control Scale (SCS, Tangney et al., 2004). The SCS is the most widely used measure of trait self-control in the last 15 years (de Ridder et al., 2012), specifically designed in accordance with the idea of inhibitory self-control. Typical items are "I am good at resisting temptation,” and "People would say that I have iron self-discipline.” This measure equals an ability self-concept of self-control. However, it does not ask whether individuals act self-controlled at all in order to reach their goals, in line with the notion of effortful self-control underlying the ego-depletion effect. With regard to the latter, Kuhl and Fuhrmann's (1998) self-discipline subscale of their Volitional Component Inventory (VCI) seems to have more content validity. Therefore, we slightly adapted this measure to capture the extent to which acting self-controlled is typical for individuals. Item examples are: "In many things that I do, I have to put a lot of pressure on myself," and "I need to pull myself together a lot in my everyday life in order to persist in something."

In Study 1 ( $N=228$ university students, 57\% female), we related the classic Tangney et al. (2004) measure and the Kuhl and Fuhrmann (1998) measure of self-control to one another, and to a measure of intrapsychic conflict (i.e., low self-concordance), and psychological well-being. We expected reverse relationships between both self-control measures, and consequently, opposing relationships with regard to experiences of intrapsychic conflict and psychological well-being.

Findings were as expected. The more individuals reported being "good" at self-control, the less typical was it for them to "act” self-controlled, yielding a large effect size. Fittingly, whereas the traditional SCS yielded a medium-sized negative relationship with experiences of intrapsychic conflict, the acting selfcontrolled measure showed a large positive relation. With regard to psychological well-being, we found the expected opposing relationships for both measures. In sum, “acting” self-controlled was a negative, and was 
the larger predictor for positive affect and life satisfaction, whereas being "good" at self-control yielded a smaller incremental, yet positive, effect.

These findings corroborate recent findings showing that the most widely used measure of self-control goes astray to the common conceptual understanding of self-control as effortful inhibition (cf., Saunders et al., 2018). This means that the positive effects that are typically found for the SCS (e.g., academic functioning, social adaptation, well-being) cannot be attributed to the assumed capability (i.e., inhibition strength). Rather, it appears that self-reported self-control strength goes along with low intrapsychic conflict experiences, which questions the need for self-control and opens the door for alternative interpretations.

In our second study, we therefore had two aims. First, we wanted to transfer the findings from Study 1 to everyday experiences of effortful inhibition using an experience-sampling approach. Second, we wanted to shed light on potential motivational processes that may explain the effects typically found for self-reported self-control as measured by the SCS. Specifically, we asked university students ( $N=114,80 \%$ female) to report on their everyday activities six times per day over one week. On the situational, within-person level (Level 1; $N=4,481$ ), we asked what they were doing (activity context), why they were doing it (degree of self-determination, see Grund, Grunschel, Bruhn, \& Fries, 2015), and the extent to which they had "to fight inner resistances" while doing it (effortful inhibition). We also measured their current affect using the Short Scale of Positive and Negative Activation and Valence (PANAVA, Schallberger, 2005). On the betweenpersonal level (Level 2), we used the same two measures of self-control as in Study 1.

Findings generally corroborated those from Study 1. Only Kuhl and Fuhrmann's (1998) typicality measure of acts of self-control predicted everyday acts of effortful inhibition in multilevel analyses. For Tangney et al.'s (2004) SCS, we found no general incremental Level 1 effect. In addition, momentary selfdetermination served as a powerful Level 1 predictor of everyday acts of effortful inhibition. The more selfdetermined an activity was perceived, the less acts of effortful inhibition participants reported.

We also found that both between- and within-differences in acts of self-control explained incremental variance in momentary affect. That is, the more participants indicated that acting self-controlled was typical for them, and the more participants reported acts of effortful inhibition in a given moment, the worse was their current affect. Controlling for these effects, we found no incremental Level 2 effects of selfreported self-control measured via the SCS on momentary affect.

Interestingly, we found context-depended patterns for the SCS. Specifically, we found that activity context moderated the effect for the SCS on momentary acts of self-control. The more self-control strength participants reported in general, the less they reported that they applied effortful inhibition during studyrelated activities, but the more effortful inhibition they reported during leisure-related activities. In addition, between-person differences in self-reported self-control strength also predicted engagement in study at the cost of leisure activities.

Taken together, these findings show that effortful inhibition is not among those processes that may explain how students high (compared to low) in self-reported self-control strength manage their life in general (cf., Saunders et al., 2018). Instead, we found that "self-controlled" students experience less intrapsychic conflict, hence, generally face low inner hindrances, which only would require self-control. We also found evidence that acting self-controlled in terms of effortful inhibition is not beneficial for well-being, neither as 
a general practice nor as a task-specific form of action regulation. The negative relation to momentary selfdetermination also highlights effortful inhibition as a self-discordant modus of engagement, in line with the idea of ego depletion (Muraven et al., 1998).

\subsubsection{Motivational foundations of self-control and mindfulness and their role in study-leisure conflicts} (Grund \& Senker, 2018)

What remains somewhat puzzling is why "self-controlled" students show better academic adaption. In another set of cross-sectional studies, we gathered evidence showing that this may not be because these students are more able to study (i.e., in terms of self-regulation skills), but because they want to study more. Taking up the idea of conflicting action tendencies that may impair ongoing study (and leisure) behavior (see Chapter 1), we reasoned that students who ascribe to themselves a high self-control strength possess a specific motivational pattern in value orientations that reduce motivational interferences from the beginning, rather than that these students actively inhibit upcoming temptations during goal pursuit. Hence, we reasoned that in would not require an extra self-control capability to facilitate goal achievement when the motivational fundament is optimal (and given sufficient intellectual capacity). Specifically, in line with Berkowitz (1996), Kohn (2008), and Kuhnle, Hofer, and Kilian (2010), we assumed that certain normative beliefs regarding effort, work, recreation, and social norms stand implicitly behind the idea of self-control, reflecting the relative importance of "business before pleasure". In this regard, interindividual differences in value orientations are crucial because they represent such normative beliefs about "good" or "right” living (Hofer et al., 2007; Hofer, et al., 2011; Schwartz, 1992).

In our first study, we wanted to replicate the findings from Kuhnle et al. (2010), showing that selfreported self-control, in terms of the ability to delay gratification, goes along with a higher achievement value orientation and a lower well-being value orientation among school children. With a different set of measures (e.g., the SCS for self-control), we found the same pattern among university students ( $N=196,62 \%$ female), yielding correlations medium in size. The more self-control students reported being, the more they favored study-related over leisure-related activities, in line with the phrase "business before pleasure," where "before” does not refer to a timely sequence, but a general preference.

Giving that motivational interference in study-leisure conflicts should be especially large only when both value orientations are held to a similar, and rather high, extent (Fries et al., 2005), we saw a relatively low conflict potential for "self-controlled" students. Hence, differences in value orientations, and not a capacity for inhibitory self-control, might explain why students high (compared to low) in self-control are academically successful. We tested this hypothesis by investigating the incremental effects of self-reported self-control, as measured by the SCS (Tangney et al., 2004), on indicators of motivational interference in a typical study-leisure conflict, as described in Chapter 1 (cf., Grund et al., 2016), while controlling for interindividual differences in achievement- and well-being value orientations.

In another sample of university students ( $N=306,68 \%$ female), we first replicated the specific diametrical pattern of value orientations in relation to self-reported self-control. The more self-control students ascribed to themselves, the more they favored achievement values and the less they favored wellbeing values, this time yielding medium to large effect sizes. Fittingly, self-control was related to lower post- 
decisional impairments as an indicator of motivational interference, but only when the decision in the conflict scenario had been in favor of studying, and at the cost of the leisure alternative. Importantly, when we entered self-control (and mindfulness, see Chapter 3) and value orientations as parallel predictors for post-decisional impairments in a linear regression model, we found that the initial effect for self-control was reduced, indicating a substantial confoundation between the variables.

In a third study ( $N=160,66 \%$ female), we were able to corroborate this confoundation. We investigated whether the assumed preference for studying over the leisure alternative in a specific studyleisure conflict would explain why "self-controlled" students report low post-decisional impairments specifically when the decision had been for the studying alternative. In other words, we assumed that this effect does not reflect that students high (compared to low) in self-control are better able to inhibit the leisure temptation. From our perspective, it simply reflects that these students think that when it comes to the crunch, studying and achievement are more important than, for example, hanging around with friends.

Indeed, in multiple regression analyses, we could show that the initial effect of self-reported selfcontrol on post-decisional impairments became insignificant when we controlled participants' preference for either the studying or the leisure alternative in the specific study-leisure conflict. Remarkably, whereas the initial effect of self-control on post-decisional impairments during studying was negative, as would be expected, the initial effect was positive with regard to post-decisional impairments during leisure time. Hence, when studying and leisure time clashes, being "self-controlled” seems to relate to less impairments in mood, and a lower distractibility during studying, because it goes along with a preference of the studying over the leisure alternative. But for this same reason, being "self-controlled" seems to relate to more impairments in mood and a higher distractibility during leisure time. 


\subsection{Summary}

Our research made clear that self-control has a lot to do with intrapsychic conflict experiences, well-being, and academic achievements. However, the interpretation of these relationships and the assumed mechanisms that underlie these relationships need to be critically questioned. There is little indication of self-control as typically defined. Being "self-controlled" does not involve actively inhibiting an upcoming inner hindrance. Self-control, as measured by the common Self-Control Scale (SCS, Tangney et al., 2004), does not involve effortful inhibition in everyday life (cf., Saunders et al., 2018). In addition, the SCS relates to low intrapsychic conflict experiences, indicating that "self-controlled" students typically face lower inner hindrances and, in this sense, act rather self-concordantly. This seems to be especially the case during study-related activities. This points to the alternative-motivational explanations for alleged effects of self-control strength. "Selfcontrolled" students show a specific pattern in value orientations that seem to explain, at least to some extent, why they show a better self-regulation (i.e., higher persistence, less distraction) in academic contexts. However, when self-control is indeed measured as effortful inhibition of inner hindrances, we clearly see the psychological costs of such a form of action regulation (i.e., in terms of psychological well-being), which can also be explained in motivational terms. Such self-control (and not self-control) equals goal maintenance at the cost of self maintenance, and carries the risk of alienation from deeper self-relevant entities, such as implicit values, motives, and needs (cf., Kuhl \& Fuhrmann, 1998; see also Chapter 4).

Taken together, we found little support for an extra self-regulatory capability of inhibition strength. Critically, this specific quality of self-control would only be of additional value when facilities (or difficulties) in goal-related experiences and performances are explained beyond motivational (i.e., to what extent and why individuals want to do something) and intellectual parameters (i.e., to what extent are individuals able to solve task-related problems). It is only when individuals are sufficiently motivated and possess sufficient task-related capacities, and still would fail to bring their goals to fruition, that we can think about an additional capability of self-control, whatever this capability may then actually consist of. So far, we have looked into some alternative motivational explanations (i.e., value orientations, self-concordance). I would argue that considering other motivational factors—such as willingness to adhere to authorities (i.e., conformism), together with intellectual capabilities—should suffice to explain experience and behavior in self-regulated learning. 


\section{Chapter 3. Mindfulness: Self-Regulation as Insight and Emotional Non-Reactivity}

\subsection{State of the literature}

Compared to the notion of self-control, the concept of mindfulness emerged somewhat later in the psychological literature (see Table 1), however, its roots reach back to ancient Buddhist meditation practice (cf., Bishop et al., 2004; Kabat-Zinn, 2003). In the last ten years, scientific publications on mindfulness have virtually exploded, and this interest is also reflected in more than 107,000,000 google hits (November 2018).

Mindfulness is of interest to the present habilitation project for two reasons. First, similar to the notion of self-control, mindfulness seems to be beneficial for well-being and self-regulation in general (e.g., Brown, Ryan, \& Creswell, 2007). However, the processes that seem to underlie these effects seem quite different compared to those assumed for self-control. Hence, mindfulness serves as an informative alternative perspective, against which the idea of self-control—as a distinguished self-regulatory capability of inhibition strength—can be scrutinized. Second, mindfulness seems to encompass or promote awareness processes that should be especially relevant in educational contexts, and for the specific self-regulatory challenge of dealing with multiple action tendencies (i.e., study-leisure conflict). However, research on mindfulness, until now, has been scarce in educational psychology.

Mindfulness refers to a receptive, non-judgmental present-moment awareness of what happens in us and to us (Baer, Smith, \& Allen, 2004; Brown \& Ryan, 2003; Kabat-Zinn, 2003). Hence, it describes a specific quality of attention and awareness. Typically, two interrelated, defining core features of mindfulness are distinguished: an unbiased orientation toward the present (i.e., what is) and an emotional-behavioral flexibility toward these perceptions (Bishop et al., 2004; Carlson, 2013; Sauer, Lynch, Walach, \& Kohls, 2011). Hence, ideally, when being mindful, individuals monitor inner and outer stimuli without relying on pre-established conceptual filters, and they are able to respond emotionally calmly to these stimuli. This enables a more integrated and genuine picture of reality, and extends one's possible courses of action, thereby serving self-regulation. For example, mindful individuals should be better connected to their implicit need and motive structures (Brown \& Ryan, 2003; Strick \& Papies, 2017), and should show less automatic reactions - that is, unconditional "(non-) wanting” in terms of either craving ("I must have this!”) or aversion (“This must go away!”) (Sauer et al., 2011).

Although being mindful refers to a specific momentary quality of consciousness, it was also argued that individuals differ in their natural capability to be mindful (Brown \& Ryan, 2003). By far, the largest amount of research on, and practice of, mindfulness concerns questions typical for clinical psychology, and shows that mindfulness is related to, or improves, well-being and prosocial behavior (e.g., Baer et al., 2004; Barnes, Brown, Krusemark, Campbell, \& Rogge, 2007; Bowlin \& Baer, 2012; Brown \& Ryan, 2003; Lakey, Campbell, Brown, \& Goddie, 2007). Empirical studies on mindfulness in the educational context are rare, despite an emerging common interest in contemplative pedagogical practices (Roeser \& Peck, 2009; Shapiro, Lyons, Miller, Butler, Vieten, \& Zelazo, 2015; Waters, Barsky, Ridd, \& Allen, 2015).

Interestingly, mindfulness and self-control, when conceptualized as stable personality characteristics and assessed via self-reports, seem to go along with quite similar positive effects (de Ridder et al., 2012; 
Brown et al., 2007). Some researchers actually reasoned that both concepts might draw on each other. For example, Bowlin and Baer (2012) found medium to large correlations between trait mindfulness and Tangney et al.’s (2004) Self-Control Scale. Yusainy and Lawrence (2014), using a different measure for mindfulness, found that self-reported self-control served as a mediating variable between self-reported mindfulness and several aspects of aggression. Fittingly, Friese, Messner, and Schaffner (2012) found that mindfulness can benefit self-control, showing that a short mindfulness intervention counteracted ego-depletion effects (see also Yusainy \& Lawrence, 2015).

When looking at the conceptual roots of both concepts, these findings are somewhat puzzling. Of course, some similarities appear at the surface level. Both constructs describe conscious modes of awareness that seem to stabilize action regulation. However, according to Brown et al. (2007), self-consciousness encompasses two capabilities: monitoring and control. Monitoring serves an observational function, whereas control serves goal attainment. Theories of reflexive self-consciousness focus on the latter function, describing how the organism decides which stimuli to monitor (and which not) in the service of goal pursuit. The notion of inhibitory self-control seems to fall into this category (although I tried to argue in Chapter 2 why I think that motivational variables are better able to explain the effects typically associated with selfcontrol strength). By contrast, mindfulness is about a receptive monitoring, where pre-established, selfcentered filters are negligible, and goal attainment at any cost would rather equal automatic, and hence, mindless behavior. Initially, there are no "right” or "wrong” experiences; there are just experiences (Baer, 2003). Moreover, it is not the aversive internal states per se that are changed (as implied in the notion of inhibitory self-control), but how an individual reacts to and perceives these states (Shapiro, Carlson, Astin, \& Freedman, 2006). Consequently, mindfulness seems to go along with less resistance to desires, and less suppression, as a general self-regulatory strategy (Friese \& Hofmann, 2016).

It struck me that both self-control and mindfulness, although conceptually distinct and maybe even antithetic in terms of the self-regulatory principles that are assumed for both concepts, are seen as the hallmark of good and happy living (e.g., Brown \& Ryan, 2003; Tangney et al., 2004). Whereas the notion of self-control proposes a certain way of acting that helps individuals to stay on track and happy, the notion of mindfulness offers a certain way of being to answer similar questions (cf., Teasdale, 1999). Therefore, I was eager to learn more about their mutual relation and about their incremental effects when observed in parallel. Given what we already know with regard to the underlying principles of self-reported self-control strength (see Chapter 2), I figured that the analysis of mindfulness would be especially insightful with regard to the challenge of dealing with multiple action tendencies, and specifically, with study-leisure conflicts. By this, I also wanted to tap the timely concept of mindfulness for educational psychology. 


\subsection{Contribution of the habilitation project}

3.2.1. Torn between want and should: An experience-sampling study on motivational conflict, well-being, self-control, and mindfulness (Grund, Grunschel, Bruhn, \& Fries, 2015)

We first wanted to know whether interindividual differences in mindfulness (along with self-control) predict everyday experiences of motivational conflict (want and should conflicts, see Chapter 1). We reasoned that a mindful stance toward one's action decisions should reduce both conflict experiences in everyday life. Generally, if one acts in harmony with oneself and the surrounding world, there should be little reason to question one's decisions in hindsight, in terms of what one would rather like doing and in terms of what one should be doing. In line with research on goal conflict (see Chapter 1), we further reasoned that lower daily conflict experiences would serve as a mediator between trait mindfulness and psychological well-being. Finally, we investigated whether these effects exist independent of participants' self-perceptions of selfcontrol, as a potential alternative explanation.

To test these assumptions, we set up an experience-sampling study (see also Grund, Schmid et al., 2015; Section 1.2.1). Six times per day over one week, participants ( $N=58$ university students, $69 \%$ female) provided answers on want and should conflict experiences, as well as their momentary affective well-being. In addition, we asked them prior to the experience-sampling period about their general mindfulness tendency and their self-control strength. With regard to the former, we relied on a widely used measure developed by Brown and Ryan (2003), the Mindful Attention and Awareness Scale (MAAS), which focuses on the being present aspect of mindfulness. Self-control we measured by the above described Self-Control Scale (SCS, Tangney et al, 2004). Finally, we assessed participants' general life satisfaction after the experience-sampling period.

We aggregated the Level 1 (i.e., situational level) variables and calculated separate mediation models for aggregated affect and life satisfaction as criteria. Mindfulness and self-control served as parallel predictors, whereas both aggregated want and should conflict experiences served as parallel mediators. We found an indirect effect of mindfulness on life satisfaction via everyday should conflict experiences, independent of participants' self-control. The more mindful participants reported being, the less intense were their should conflict experiences in everyday life, which, in turn, related to higher life satisfaction. Mindfulness also emerged as a substantial direct and positive predictor for aggregated affective well-being. However, we found no indication of mediation via want conflicts.

Although want conflicts are more common during studying activities and should conflicts are more common during leisure time (Grund, Schmid et al., 2015; Riediger \& Freund, 2008), both ways of assessing and classifying motivational conflicts are not completely congruent. Therefore, we wanted to transfer the above findings to situations of study-leisure conflict, as described in Chapter 1 and Chapter 2. More specifically, we wanted to use the concept of mindfulness to point to differential motivational processes that may help students to deal with conflicting action tendencies during studying and leisure time. 


\subsubsection{Motivational foundations of self-control and mindfulness, and their role in study-leisure conflicts} (Grund \& Senker, 2018)

The present description refers to the same study as described in Chapter 2.2.3. This time, however, we have focused on mindfulness, and not self-control, as the central variable of explanation. Different from selfcontrol, we did not assume that mindfulness functions via general a priori preferences concerning achievement and well-being values. Rather, in line with Brown and Ryan (2003), we hypothesized that being mindful enables one to be better connected to one's basic needs, which, in turn, results in situationally flexible and self-congruent behavior.

Consequently, we found that mindfulness was unrelated to achievement and well-being orientations (Study 1 and Study 2; see Section Chapter 2.2.3. for further details of the different studies). Yet, when confronted with the typical scenario of a study-leisure conflict, we found that mindfulness related to both lower post-decisional impairments during studying and leisure time, which speaks to a general action stabilizing effect of mindfulness (Study 2). Notably, this effect remained stable while controlling for selfcontrol and value orientations. Finally, in a third study, we found that mindfulness was not related to a preference for either the studying or the leisure alternative in a specific study-leisure conflict (as was the case for self-control). Consequently, different from self-control, post-decisional impairments during studying and leisure time were not mediated via such preferences. Rather, we found that the effect of mindfulness on post-decisional impairments was (partially) mediated via need satisfaction. That is, the more mindful students reported being, the more competent and autonomous they felt, which, in turn, related negatively to impairments in mood and a higher distractibility when studying was conflicted with by a leisure-related alternative, as well as in the opposite conflict constellation.

\subsubsection{Mindfulness and situational interest (Grund, Schäfer, Sohlau, Uhlich, \& Schmid, 2019)}

The concept of mindfulness has been related to learning behavior relatively early (Salomon \& Globerson, 1987). For example, Langer (2000) considered mindfulness as a functional state for learning in that it promotes "a flexible state of mind in which we are actively engaged in the present, noticing new things and sensitive to context” (p. 220). Specifically, for Langer, mindful learning consists of the act of drawing novel distinctions, which is more likely when information is recognized as being uncertain and contextualized, rather than as being absolute. In the recent educational discussion, there has also been a call for a comprehension of contemplative practices in the learning contexts (e.g., Roeser \& Peck, 2009; Shapiro, Lyons, Miller, Butler, Vieten \& Zelazo, 2015; Waters, Barsky, Ridd \& Allen, 2015). Yet, pertinent empirical studies in the field of educational psychology that corroborate this claim are relatively rare. We therefore set up this study in an attempt to exploit the concept of mindfulness for educational contexts. Specifically, we wanted to explore the extent to which dispositional mindfulness serves as an internal resource for the development of situational interest. Our reasoning assumed that, in principle, all new objects, contents, or ideas can be interesting. The elicitation of situational interest, however, is seen to mainly depend on the external support provided by others (Hidi \& Renninger, 2006). We reasoned that the specific attention and awareness qualities of being mindful may also explain students' differences in interest regarding new stimuli (e.g., texts, ideas). 
In this two-measurement point study ( $N=161$ university students, 74\% female), we used a more comprehensive measure of mindfulness compared to the Mindful Attention and Awareness Scale (MAAS, Brown \& Ryan, 2003). The Kentucky Inventory of Mindfulness Skills (KIMS, Baer, Smith, \& Allen, 2004) distinguishes between observing, describing, acting with awareness, and accepting/allowing without judgment as separate, yet somewhat related aspects of being mindful. Observing emphasizes the importance of being capable of noticing and attending to internal (e.g., cognitions, feelings) and external (e.g., sounds, smells) stimuli. Describing refers to the ability to put these stimuli and/or sensations into words, which may help to identify specific behavioral and/or cognitive patterns. Finally, acting with awareness and accepting without judgements refer to the two defining qualities of mindfulness. Acting with awareness encompasses being fully "present" and engaged in an activity with undivided attention—similar to the MAAS. Accepting (or allowing) without judgment refers to a non-judgmental, receptive form of attention toward the present.

With regard to the two latter aspects of mindfulness, it is obvious that directing one's attention to the stimuli at hand is a necessary condition of the interest experience. Hence, the general capacity to be wholeheartedly present and attend to a certain object or content should be crucial to developing situational interest. If, for example, students are predominately concerned about an upcoming exam while being confronted with a new theory, then the content itself and its possibility to elicit novel distinctions may simply be "overlooked". In order to recognize the intellectually stimulating potential of (fairly) new content, it should also be helpful to approach it non-judgmentally and receptively, that is, without self-centered conceptual filters (cf., Brown et al., 2007) or without relying on distinctions drawn from the past (Langer, 2000). Such biases may lead to overhasty evaluations of content as irrelevant, negative, or even too familiar. Without such secondary elaborative thoughts about one’s experience (Shapiro, Carlson, Astin, \& Freedman, 2006), more resources are made available to process the stimuli themselves as they are, which should result in a wider and fresher perspective of current experiences, often referred to as "beginners mind” (Bishop et al., 2004).

In our study, we assessed students' mindfulness tendency and confronted them with a factual text on bionics. Participants were then asked about their situational interest regarding the material directly after having read the text (t1) and one week later (t2).

Our findings showed that interindividual differences in mindfulness predict situational interest regarding the text on bionics. Notably, especially the abilities to act with awareness and to receptively observe internal and external stimuli showed incremental positive effects (cf., Baer et al., 2004). Moreover, these effects were especially large for affect-based aspects of interest, that is, triggered situational interest and the feeling component of maintained situational interest (cf., Linnenbrink-Garcia et al., 2010; Schraw, Bruning, \& Svoboda, 1995). We also found an indirect effect of mindfulness on participants' maintained situational interest one week later via their situational interest immediately after having read the text. Intriguingly, these effects remained stable while controlling for participants' initial interest in and knowledge about bionics.

It is noteworthy that we found no direct effects for mindfulness on value aspects of situational interest that are characterized by the perceived personal relevance of a specific content (cf., Linnenbrink-Garcia et al., 2010; Schraw, Bruning, \& Svoboda, 1995). This is in line with the notion of mindfulness as enabling a disidentification from the contents of consciousness (e.g., thoughts and emotions), and allows one to view moment-by-moment experience with greater clarity and objectivity (Shapiro et al., 2006). Hence, it seems 
that a potentially supportive effect of mindfulness on interest is mainly due to affect-based processes rather than to cognitive evaluations of personal relevance, which seems crucial for emerging and well-developed individual interest (Hidi \& Renninger, 2006).

Naturally, we cannot expect that any mindful contact with a new stimulus will sow the seed of later well-developed individual interest. Would this be the case, mindfulness, as a disposition, would likely be considered a bane rather than a boon of humanity because mindful individuals would be simply overwhelmed by the amount of different individual interests they could acquire throughout their life. In line with this reasoning, we found only a weak relation between general mindfulness and participants' initial interest in bionics. Hence, mindfulness may support the development of personal interest, not in terms of quantity, but rather in terms of quality. For example, an open-minded and receptive stance toward school subjects may result in a more differentiated pattern of personal interests (and dislikes), which may allow for more elaborate decisions for study majors which, in turn, may support self-congruent studying behavior (cf., Brown \& Ryan, 2003). 


\subsection{Summary}

The present research shows that the concept of mindfulness can serve as an informative alternative perspective against which the idea of self-control, as a distinguished self-regulatory capability, can be scrutinized. Both personal characteristics seem to go along with less intrapsychic conflict experiences. However, whereas the effect of self-control seems context specific in that it mainly fosters academic behavior - probably at the cost of the leisure experience - the effect of mindfulness seems context transcending in that both the regulation of study- and leisure-related engagement is supported. Further, given the problematic content validity of the typical self-report measure for self-control, and evidence for alternative motivational explanations for alleged effects of self-control strength (see Chapter 2), mindfulness may qualify as the better candidate for a basic capacity that supports self-regulation, independent of activating energetic processes.

In line with Brown and Ryan (2003), we found evidence that mindfulness supports self-regulation by enabling need satisfaction (Grund \& Senker, 2018). Hence, mindfulness may function in the pre-decisional phase of goal pursuit (Heckhausen \& Gollwitzer, 1987). That is, before an action is taken, mindfulness may enable a comprehensive and objective analysis of inner states. Such a clear insight (cf., Carlson, 2013) lays the ground for self-concordant decisions (Brown \& Ryan, 2003; Strick \& Papies, 2013), which should render effortful, volitional processes of goal maintenance (at the cost of self maintenance, Kuhl \& Fuhrmann, 1998) relatively obsolete. In addition to that, inner and outer hindrances that emerge during goal pursuit-for example, because one eventually finds oneself doing something that does not match one's core values (e.g., because one is obliged to do it), or one's capabilities - may have a less discouraging impact. Mindful individuals may be better able to respond emotionally calmly, being cool-headed to such experiences (Sauer et al., 2011), which enables them to have greater cognitive, emotional, and behavioral flexibility (Carlson, 2013).

In addition to these general self-regulatory mechanisms, it seems that mindfulness can benefit learning processes more directly. We found evidence that a mindful stance toward new content promotes the development of situational interest. This is in line with findings from Howell and Buro (2011), who found positive relationships between mindfulness and achievement emotions, such as enjoyment and hope. In this regard, it should be noted, however, that more tangible learning outcomes, such as grades, may not be affected by mindfulness so long as they depend largely on academic time investment, and not on qualitative learning processes (e.g., elaboration). As mindfulness, opposed to self-control, does not seem to be based on the unconditional preference of studying over leisure-related activities, we may not find a positive relation between mindfulness and academic time investment. 


\section{Chapter 4. Self-Regulation as Self-Congruent Goal Selection}

\subsection{State of the literature}

Throughout my habilitation project, I developed the impression that we need to be much more precise when we speak of self-regulation. I should denounce myself (e.g., Grund \& Fries, 2012; Grund \& Fries, 2014) as an example for carelessly speaking about (difficulties in) self-regulation, when in fact, we just spoke about what students do, how persistent they are in what they are doing, and how it feels to do what they are doing. This impreciseness is problematic because motivational theories cover the same explanatory space-that is, explaining what individuals do, how persistent they are, and how they feel (e.g., Vollmeyer \& Rheinberg, 2006). Therefore, I think it is critical to delineate motivational from self-regulatory concepts.

In this regard, it is important to note that active, deliberate self-regulation is only required if certain difficulties emerge during goal pursuit, and if the organism does not react more or less automatically to these difficulties. For example, in a state of flow, individuals act quite efficiently on quite challenging tasks, without requiring much “top-down” control (Rheinberg \& Engeser, 2018; Sheldon, Prentice, \& Halusic, 2014). Similarly, when being intrinsically motivated, children show very high persistence, without much “top-down” control (Rheinberg \& Engeser, 2018). More generally, Sokolowski (1997) distinguished motivational from volitional states of regulation. It the first case, no willful, top-down control is required. Thoughts are action focused, attention is hardly distractible, positive feelings accompany action, and effort is hardly experienced; maybe despite an objectively relatively high task complexity. Hence, in these cases, we can hardly speak of “active” self-regulation, although critical standards of self and goal maintenance are met (I should note here that automatic processes of goal maintenance and shielding are sometimes also referred to as self-regulation, e.g., Bargh, Gollwitzer, Lee-Chai, Barndollar, \& Tröschel, 2001; Koranyi \& Rothermund, 2012; Shah, Friedman, \& Kruglanski, 2002). In the second case (volitional regulation), willful control is required to direct attention to the task at hand and remain focused there while feelings of aversion arise. This is accompanied by a feeling of high effort; maybe despite the fact that task complexity is relatively low.

Sokolowski (1997) further noted that inner difficulties should be distinguished from outer difficulties in states of volitional regulation. Outer difficulties refer to capability problems, whereas inner difficulties refer to situations where goal pursuit is not supported on motivational grounds. With regard to the former, the "size" of the problem, and hence the amount of willful action that is required to solve the problem, is a function of one's current ability in relation to the task's difficulty. The poorer one's initial ability and the more difficult the problem, the more effort needs to be investigated to solve the problem (e.g., the more time needs to be invested). By contrast, with respect to inner difficulties, it is not one’s ability, but one’s motivation that is the "problem" that needs to be solved. In these cases, willful action is either required because an action is not pleasant in itself, and/or because an opposing action tendency exists (e.g., habits, test anxiety, more pleasurable activities). Similarly, inner difficulties need to be overcome if someone has to suppress a pleasant action (e.g., eating a tasty donut). 
Given the conceptual difference between motivational and volitional regulation, as well as the difference between dealing with inner and outer difficulties, it is important to know how these different qualities of regulation relate to each other. However, questions such as these have been seldom sufficiently addressed. For example, although motivational and volitional processes are explicitly distinguished in the Rubicon Model of Action Phases (Achtziger \& Gollwitzer, 2018; Gollwitzer, 1990; Heckhausen \& Gollwitzer, 1987), it remains somewhat unclear how and whether volitional processes of planning and action control are seen to depend on earlier motivational pondering processes that precede a goal intention. Interestingly, Heckhausen and Gollwitzer (1987) found that task irrelevant thoughts during action (e.g., thoughts about unfinished businesses or about one's mood and needs) were more prevalent when subjects were assigned to a task than when they had free choice between two materials. This points to a motivational dependency of (automatic) volitional processes, such as goal shielding (Shah et al., 2002). Similarly, the notion of motivation regulation (e.g., Schwinger, Steinmayr, \& Spinath, 2009; Wolters, 2003) implies that motivation can be an object of volitional control, similar to cognitive processes. However, these socialcognitive perspectives also leave open critical questions about the relationship between motivational and volitional regulation, for example: Why am I not motivated to study, but motivated to enhance my study motivation (i.e., motivation regulation)? Is such a form of regulation different from a willingness to engage in studying out of extrinsic or introjected reasons, or from a willingness to comply with authorities and prevalent societal norms?

In everyday life, it is also likely that inner and outer difficulties do not exist independently from each other. For example, repeated failures due to a lack of knowledge or inadequate learning strategies may impact motivational variables, such as expectancy and value appraisals (cf., Boekaerts, 1997). However, suboptimal motivational processes are likely to impede access to, and the application of, adequate learning strategies. Knowledge about the situationally adequate application of learning strategies is an example of a meta process that refers to dealing with outer difficulties (Boekaerts, 1997), and in this sense, may qualify as a selfregulatory capability that can be distinguished from other, more direct, task-related capacities, such as intelligence or prior conceptual and procedural knowledge. The critical question is whether we can identify similar meta capacities for dealing with inner difficulties that can be distinguished from basic motivational variables, such as values and expectancies.

Indeed, dealing with inner difficulties (i.e., motivational problems) is the core theme in research on self-control, procrastination, and motivational regulation. Hence, in this regard, it is of special importance to make sure that self-regulation theory does not encroach too far upon motivation territory. So far, however, the focus has been on demonstrating incremental validity of self-control strength as a distinguished capability with respect to general intellectual capabilities (Duckworth \& Seligman, 2005; 2006), and not with respect to motivational variables. In Chapter 2, I argued that interindividual differences in value orientations may account for the effects typically interpreted as self-control strength. In the following, I transfer this reasoning to scrutinize the typical understanding of procrastination as a self-regulatory failure by offering a motivational perspective to this infamous phenomenon. This involves questions about the energetic fundament of goal-related activity. Hence, whereas most research on self-regulation is concerned with (volitional) questions of goal maintenance (cf., Kuhl \& Fuhrmann, 1998), we scrutinized the motivational 
I Synopsis: Chapter 4. Self-Regulation as Self-Congruent Goal Selection

basis of these goal intentions. I also discuss why I see mindfulness, different from the concept of self-control strength, as a veritable self-regulatory capability that helps individuals make self- and motive-congruent decisions, which is in line with the idea of motivational competence (cf., Rheinberg \& Engeser, 2010). 


\subsection{Contribution of the habilitation project}

\subsubsection{Understanding procrastination: A motivational approach (Grund \& Fries, 2018)}

Procrastination typically refers to an intention-action gap (Klingsieck, 2013; Steel, 2007). It appears as if individuals act against their good intentions; a fascinating phenomenon which has been known for a long time in philosophy as akrasia, or weakness of will (Stroud, 2010). As an exact antipode to the idea of selfcontrol strength, a common understanding of procrastination is that something enigmatic and irrational occurs in the time between setting an intention and acting this intention out. "Procrastinators" seem to lack selfregulatory capabilities, such as self-control (Rebetez, Rochat, Barsics, \& van der Linden, 2016; Schouwenburg \& Groenewoud, 2001), emotion regulation (Eckert, Ebert, Lehr, Sieland, \& Berking, 2016), motivation regulation (Grunschel, Schwinger, Steinmayr, \& Fries, 2016), time management (Wolters, Won, \& Hussain, 2017), and learning strategies (Howell \& Watson, 2007; Wolters, 2003), which allow them to successfully act out their intention. The goal intention itself is not questioned.

Our idea was to show that these "insufficient" volitional processes, which mainly regard the planning and action phase according to the Rubicon Model (Heckhausen \& Gollwitzer, 1987), may depend on earlier suboptimal motivational processes. We simply ask: Do individuals really want what they intend to do? In line with the notion that "not all goals are personal goals" (Sheldon \& Elliot, 1998), we propose a straightforward motivational explanation of procrastination. From our perspective, procrastination itself (i.e., the delay) is not irrational or enigmatic at all, but occurs when individuals pursue goals that are not in line with their personal values and basic needs.

In Study 1, we took a similar approach as that described in Grund and Senker (2018, see Chapter 3). In that study, we expected that interindividual differences in self-ascribed self-control strength may be confounded by a specific pattern in value orientations, approving achievement values to a relatively high extent, and well-being values to a relatively low extent. In the present study, we expected the exact opposite value pattern with regard to interindividual differences in academic procrastination.

In a correlational study ( $N=223$ university students, $66 \%$ female), we found the expected pattern. Students who indicated a higher tendency for academic procrastination also indicated a lower achievement value orientation and a higher well-being value orientation, whereas the effect for the former was large and the effect for the latter was small. Given the assumed energetic and directional function of values as warm beliefs (Schwartz, 1992), and given further the close connection between academic procrastination and motivational interferences in study-leisure conflicts (Grund et al., 2014), we can assume that the motivational basis of "procrastinators" is suboptimal with regard to an unconditional focused attention on studying at the cost of leisure time. Notably, this is different from the interpretation that individuals high in academic procrastination are not able to prefer studying over leisure time. Such a reasoning would presuppose that all individuals are equally motivated to study and to engage in leisure time.

In our second study, we took a different approach to verifying the assumed motivational foundation of procrastination in several ways. First of all, we investigated the motivational fundament of action from a different theoretical perspective - that is, with regard to Self-Determination Theory (Deci \& Ryan, 2000)— and not with regard to value orientations. Second, we did not concentrate on between-person differences in 
motivation and procrastination only, but also regarded within-person differences. Related to the latter point, we took a diary approach and concentrated on everyday intentions and behaviors rather than on general procrastination tendencies. Similar to our first study, we were interested in the extent to which individuals actually "wanted" what they intended to do, thereby separating the reasons for engagement, which can be considered the energetic basis of engagement, from the ends at which these engagements are aiming (cf., Sheldon \& Elliot, 1998; Thrash \& Elliot, 2001). In line with the assumption that self-determined behavior fosters persistence, we expected that within-differences in self-determination are related to activity completion (i.e., dilatory behavior), as an indicator of procrastination.

We asked 35 university students (77\% female) to write in a diary over one week about their daily intentions and their attainment, resulting in a total 973 daily projects. Following Grund, Grunschel et al. (2015, see Chapter 3), we asked them each evening to rate the degree of self-determination for each intention, and to what extent they achieved what they intended to do. We also assessed their general procrastination tendency. Using multilevel modeling, we found that activity-specific self-determination served as a significant Level 1 (i.e., within-person) predictor of activity completion. The less self-determined an activity was perceived as being, the more likely it was that participants did not achieved what they intended to do for this day. We also found that participants' general procrastination tendency served as a significant Level 2 (i.e., between-person) predictor for activity-specific self-determination, meaning that the more students identified themselves as "procrastinators", the less self-determined they perceived their daily engagements.

As with all correlational studies, we cannot be sure about the direction of these relationships. It could be, for example, that students reported a biased picture of the self-determined nature of delayed activities and their daily intentions in hindsight, to legitimate their behavior. This, however, would not explain the connection between participants' general procrastination tendency and everyday self-determination. Rather, it appears that "procrastinators" feel somewhat alien with regard to their daily engagements, which speaks to a suboptimal motivational fundament of their actions.

In Study 3, we took quite a different perspective on the phenomenon of procrastination and its motivational interpretation. Whereas we explored the motivational basis of individual procrastination in Study 1 and Study 2, we took a more sociological perspective to understand why the idea of procrastination as self-regulatory failure is so pervasive. Complementary to our assumption that the idea of self-control strength as an explanation for extraordinary success (cf., Duckworth \& Seligman, 2005; 2006) is driven by a certain normative perspective, paraphrased as business before pleasure (see Chapter 2), we reasoned that a similar ideology may drive the idea of procrastination as self-regulatory failure.

Drawing on research from social psychology (e.g., Skitka, Mullen, Griffin, Hutchinson, \& Chamberlin, 2002), we reasoned that different ideological beliefs and values are related to different attributions of procrastination as a personal weakness (in line with the notion of procrastination as selfregulatory failure), or as being dependent on situational causes. We expected that the attribution of dilatory behavior in academic contexts to a dispositional cause, rather than to changing situational circumstances, is more likely to occur for modern, conservative beliefs (i.e., achievement value orientation, conservatism, and protestant work ethic), but not for post-modern, liberal beliefs (i.e., well-being value orientation and liberalism). 
We confronted 201 students (50\% female) with a scenario of academic procrastination (i.e., not studying on the weekend despite the intention to do so; meeting friends instead; having a bad conscience) that mirrored typical definitions of procrastination (cf., Klingsieck, 2013). Participants were then asked which of two explanations seemed most likely to explain the depicted behavior. One explanation represented a dispositional cause, implying personal responsibility and control (i.e., "The student does not have enough self-discipline"), and the other explanation represented a situational, external cause ("The student recently had little time for his/her friends”). We then assessed participants’ ideological values and beliefs by selfreports.

In line with previous findings on the attribution of social problems and alleged misconducts, such as crime, poverty, homelessness, unemployment, and obesity (e.g., Carroll, Perkowitz, Lurigio, \& Weaver, 1987; Crandall, 1994; Pellegrini, Queirolo, Monarrez, \& Valenzuela, 1997; Skitka \& Tetlock, 1992), we found that participants with more conservative attitudes, and those who approved the protestant work ethic to a greater extent, were more likely to attribute the instance of academic procrastination to a personal failure. By contrast, participants who entertained liberal and well-being values to a greater extent were more likely to attribute the instance of academic procrastination to situational circumstances, although the vast majority of the sample chose the personal cause. Therefore, effect sizes were generally small.

We took these findings as initial evidence that the discussion on procrastination, similar to the discussion on self-control strength, is biased by a specific moral perspective in line with a modern, conservative ideology of the "right” way of living (Berkowitz, 1996; Kohn, 2008). Such a perspective denies interindividual differences in general motivational tendencies and implies that all individuals (should) want and strive for the same things.

In the last work of this habilitation project, we tried to argue for a perspective on self-regulation that acknowledges such differences and that explicitly addresses the energetic role that needs play in relation to goal pursuits. Furthermore, by delineating capabilities that may operate independently from motivational forces, we hoped to contribute to gaining a clearer, less biased picture of phenomena typically considered as self-regulatory failure or strength.

\subsubsection{Know Your Preferences: Self-regulation as need-congruent goal selection (Grund, Fries, \& Rheinberg,} 2018)

This conceptual paper aimed at highlighting a certain blind spot and bias typical in social-cognitive models of self-regulation, and providing ideas to further our understanding of self-regulation in a more comprehensive sense. In a way, it also served as an attempt to integrate some of the major ideas I presented in the Chapters 1-3.

I was struck by the impression that ideas from classic motivation research and ideas from research on self-regulation arrive at fundamentally different conclusions with regard to intrapsychic conflicts as a threat to goal pursuit and well-being. In the former case, intrapsychic conflict is seen as an instance of suboptimal motivational processes that need to be solved in terms of self-integrity or -congruence, thereby indirectly promoting goal pursuit and well-being (e.g., Brunstein, 2018; Kuhl \& Fuhrmann, 1998; Sheldon, 2014; Thrash \& Elliot, 2002). In the latter case, intrapsychic conflict is seen as an instance of self-regulatory 
failure and attempts to solve the issue by creating a focus on effortful, volitional control processes that actively suppress affect-based responses of the organism, which run counter to goal maintenance, thereby reestablishing well-being (e.g., Baumeister, Gailliot, DeWall, \& Oaten, 2006; Baumeister \& Heatherton, 1996; Hofmann et al., 2012; Tangney et al., 2004). Hence, whereas motivation research focuses on the selfmaintaining function of self-regulation (cf., Kuhl \& Fuhrmann, 1998) and has less to say about the specific capabilities, or rather competencies (see below), that enable individuals to achieve such self-integrity, selfregulation research focuses on the goal-maintaining function of self-regulation without referring to basic energetic motivational processes that may or may not support persistence.

Drawing on Rheinberg and Engeser's (2010; 2012) idea of motivational competence, we tried to bridge these discrepancies by identifying competencies that enable individuals to select goals that fit their underlying needs, thereby aligning the reasons and ends of behavior (cf., Thrash \& Elliot, 2001). The idea of motivational competence is in line with the idea that human behavior is most effective when implicit needs and explicit motives operate in harmony (Brunstein, 2018; Sheldon, 2014; Thrash \& Elliot, 2002). However, it is also in line with the well-known finding that implicit and explicit motivational tendencies do not converge naturally for all individuals (McClelland, Koestner, \& Weinberger, 1989; Spangler, 1992; Thrash, Elliot, \& Schultheiss, 2007). Hence, from a self-regulation perspective, it is critical to ask what competencies may help individuals to achieve such congruence. Importantly, different from a social-cognitive perspective that places an emphasis on post-decisional (i.e., volitional) control processes to enable goal pursuit despite momentary affective setbacks (cf., Baumeister et al., 2006; Fishbach \& Shah, 2006), such competencies would initially regard processes that enable a need congruent goal selection. Hence, according to the Rubicon Model (Heckhausen \& Gollwitzer, 1987), we should speak of motivational (Rheinberg \& Engeser, 2010), rather than volitional, competencies because such competencies regard pre-decisional processes. Nevertheless, I see them as self-regulatory capabilities because they refer to meta knowledge that has the potential to reduce inner hindrances, thereby enabling a better self and goal maintenance (cf., Kuhl \& Fuhrmann, 1998).

Rheinberg and Engeser (2010; 2012) proposed several such competencies. First, and most important, individuals need to know about their implicit motives and needs. This is by no means a trivial endeavor, given that motives are typically not a part of the explicit motivational self-concept. This, however, does not mean that, in principle, we can know and tell what we need (Weinberger \& McClelland, 1990). Given that we know about our implicit motives and needs, a second competence refers to the ability to prospectively "read" the incentive structure of upcoming situations, activities, and outcomes in terms of their motive congruency. Only when individuals can validly appraise the satisfying potential of what will be in the future are they able to make motive-congruent decisions. Third, especially in long-term projects, such as academic studies and career, motivationally competent individuals not only consider the potential benefits that result from their completion (i.e., incentives attached to the consequences of activities and their outcomes), but also the gratification that derives from the means of achieving these instrumental incentives (i.e., activity-specific incentives). Otherwise, goal pursuit may become too burdensome. Fourth, metacognitive knowledge about the internal and external conditions that may influence one's (automatic) motivational processes is helpful. For example, it may be critical to know that societal movements shape the perceived desirability of an 
outcome and its consequences (e.g., holding an academic degree). Finally, if necessary, individuals should be able to endow current situations with motive-congruent incentives. Even when we assume the most optimal decisions, individuals may now and then find themselves in situations where their actions are not automatically supported by positive affect (i.e., by implicit motives and needs). In order to maintain both goal pursuit and self-integrity, it is therefore necessary that individuals purposefully re-align both processes by shaping situations and activities so that they better fit their motive structure. Such a competency, however, would not regard the pre-decisional action phase, but most likely the action phase itself (Heckhausen \& Gollwitzer, 1987). Nevertheless, we can still regard it as a motivational competency that serves selfregulation because it refers to meta knowledge about our basic motivational processes.

What can individuals do to acquire such meta knowledge about their implicit needs and motives? Rheinberg and Engeser (2010) speculated that imagery exercises and retrospective self-diagnoses should focus on specific situations and required activities rather than on the outcomes and consequences of these activities. This should temporarily weaken the influence of the explicit motivational self-concept (which is also shaped by rosy illusions and expectations from others), and help to gain access to one's implicit affective preferences. Such exercises may include questions such as: "Which activities (in the work context) do I favor and return to again and again even without the promise of a reward"? "When has my work been particularly unproblematic and enjoyable”? (Rheinberg \& Engeser, 2010, p. 539).

In line with this reasoning, research by Schultheiss and Brunstein (1999) and Job and Brandstätter (2009) showed that goal imagery (i.e., the experiential-like mental representation of the pursuit and attainment of a goal) strengthened goal commitment for a goal in line with individuals' implicit motives. Envisioning a situation with many sensory details, especially the anticipation of motive-specific affective incentives of future goals, is likely to result in a vivid picture of how it would be, or feel, to engage in a similar situation. For example, Job and Brandstätter (2009) asked: “... try to imagine yourself striving for it. How do you feel? Do you experience intensive positive feelings, such as joy, happiness, and pleasure, by striving for this goal?” (p. 1537). This information is crucial for helping participants gain an "affective taste" of possible goals, which, in turn, should help them to decide which goals to adopt and which to reject in order to live a satisfying life (see also Schultheiss, Patalakh, Rawolle, Liening, \& MacInnes, 2011, for a similar intervention). Only recently, Roch, Rösch, and Schultheiss (2017) developed an intervention that paralleled several of the strategies described by Rheinberg and Engeser (2010), and showed that this fosters congruence between motives and goals. Mentally contrasting positive future fantasies about goal attainment, with a reality that may impede goal attainment, may serve as another strategy to help individuals become aware of the need-satisfying potential of their wishes (Kappes, Schwörer, \& Oettingen, 2012; Oettingen \& Stephens, 2009).

In sum, these ideas and findings show the complementary, rather than oppositional, potential of affective and cognitive processes of motivation. The key to such relatively effortless forms of regulation lies in competencies that enable a considerate goal selection from the beginning (cf., Sheldon, 2014), rather than the effortful, rigid implementation of whatever goal individuals pursue. 


\subsection{Summary}

Given this knowledge about intrapsychic congruence and competencies that may promote such congruence, what can we learn about the self-regulatory problems I addressed in the Chapters 1-3? With regard to the issue of multiple and conflicting action tendencies (Chapter 1), I already mentioned that it will be important to regard the joint effect of focal and conflicting motivational tendencies because it is likely that conflict between two (or more) action tendencies depends on the motivational quality of each single action tendency, and how it relates to deeper personality structures. In this sense, self-congruence of goal-directed behavior could be viewed from a self-determination perspective (Sheldon, 2014), but also from the perspective of motive congruence (Brunstein, 2018; Rheinberg \& Engeser, 2010; Thrash \& Elliot, 2002). In both cases, alternative action tendencies may become more pressing and attractive the less implicit needs are currently satisfied. Similarly, although different types of conflict constellation seem to exist (e.g., work-home and home-work interference; want and should conflict), which seem to contribute differentially to psychological functioning (Grund et al., 2014; Grund \& Fries, 2014), general and task-specific self-congruence is likely to account for some of the general negative effects associated with conflicting action tendencies. At the end of this habilitation project, I developed the impression that especially in want-conflict situations, indeed, the energetic fundament of the "focal" action tendency seems to be the core motivational issue, and motivational interferences from other action tendencies depict rather epiphenomena in this regard. Such a reasoning, however, does not seem to be applicable to should-conflict situations because we found that intrinsic-like qualities of the focal activity are relatively high in such conflict constellations (Grund et al., 2014). Therefore, it seems promising to further differentiate and scrutinize the nature of these two types of motivational conflicts.

With regard to the notion of self-control (Chapter 2), the ambiguous nature of the concept becomes apparent from a congruence perspective because momentary affects are not only regarded as a threat to goal pursuit, but as its energetic fundament. From this perspective, any enduring goal pursuit that is experienced as effortful and tenacious (given adequate capabilities) is suspect of violating implicit motives (Brunstein, Schultheiss, \& Grässmann, 1998), and may undermine self-integrity and well-being in the long run (Kehr, 2004; Kuhl \& Beckmann, 1994). This is also implied by the term ego depletion (Muraven \& Baumeister, 2000). Studies that focus on interindividual differences in self-control strength, however, do not reflect this grueling potential of intrapsychic conflict (Hofmann, Baumeister, Förster, \& Vohs, 2012; Grund \& Carstens, 2019). Rather, with regard to Hofer et al.'s (2007) idea of value change in relation to motivational interference between studying and leisure time, we can conclude that conflict potential is relatively low for individuals who ascribe to themselves a high self-control strength because they value achievement-oriented activities to a relatively high, and well-being values to a relatively low, extent. This a priori precedence and thematic focus should facilitate decisions in everyday life, and reduce subsequent motivational interferences, especially in competitive contexts. However, it seems problematic to interpret these effects in terms of a capability. "Being able” to prefer studying over leisure time hardly qualifies as a specific skill. What exactly is it that one can do here? Shift the attentional focus? Suppress the upcoming temptation? Obviously, automatic motivational processes (i.e., motivational regulation, cf., Sokolowski, 1997) would also explain such effects, for example, render a "temptation” less attractive (Shah et al., 2002). Hence, such effects of 
self-control seem to regard energetic motivational processes more directly, which is also supported by the finding that self-control strength relates to positive affect (Hofmann et al., 2014), and not in terms of a distinct self-regulation capability.

With regard to mindfulness (Chapter 3), the situation seems different. Being mindful should enable individuals to base their daily decisions on a comprehensive and receptive situational analysis of inner and outer conditions, and to react emotionally, cognitively, and behaviorally flexible to these experiences. This insight (Carlson, 2013) and emotional non-reactivity (Sauer et al., 2011, see also Section 3.3.) seem to promote value clarification (Shapiro et al., 2006) and self-determined behavior (Brown \& Ryan, 2003). It is obvious that effective self-regulation requires a minimum of self-insight. If I do not know what I want and what I like, how can I get there? Moreover, if I do not know how I feel right now (i.e., during goal pursuit), how can I decide whether I am still on the "right” track, or whether I should change the means, or even my goal (cf., Louro, Pieters, \& Zeelenberg, 2007)? In line with this reasoning, private body consciousness has been identified as a dispositional precondition for congruence between implicit and explicit motives (Thrash et al., 2007), and the same seems to be true for mindfulness (Brown \& Ryan, 2003; Strick \& Papies, 2017). Hence, mindfulness can be considered a capability that fosters self-regulation in that it helps individuals to choose wisely (i.e., situationally adequate) and freely (i.e., independent from internal and external pressures) between options, rather than to rigidly follow one-way rules, such as business before pleasure (Grund \& Senker, 2018). Fittingly, mindful individuals have been found to rely less on effortful restraint as a selfregulatory principle (Friese \& Hofmann, 2016). Moreover, mindful individuals seem to better know what truly motivates and pleases them, and they seem to follow these "gut feelings" despite other potentially rivaling internal and external forces. In that, a mindful mode of awareness should depict a helpful precondition for some of the motivational competencies proposed by Rheinberg and Engeser (2010). 


\section{Chapter 5. Self-Regulation as Acquisition and Application of Meta Knowledge}

\subsection{Self-regulation through meta-knowledge}

The term self-regulation carries with it many implications, one of which is the existence of central executive which operates independently from energetic motivational forces, and therefore has "control" over these forces, similar to a skillful horseman who rides a wild stallion (cf., Weinert, 1987). Another implication related to the first one is that if one is not motivated to do something, one can make oneself be motivated. Based on my above analysis, I think that such views of self-regulation are problematic because ideas about "skill" and "will” are confounded here (i.e., self-control as a skill to will). I doubt the idea that self-regulation processes enable us to deliberately "change" or "choose” our energetic motivational processes directly. I therefore suggest that the term self-regulation is maybe best used exclusively when referring to initiation of monitoring processes that promote the acquisition of conditional meta knowledge about one's "skill" and "will"-that is, about idiosyncratic and situation-specific capabilities and motivational processes, respectively. Such self-related insight, in the form of a birds-eye view of one's capabilities, idiosyncratic values, and expectancies, as well as their situational dependency and adequacy, is promoted by first-hand information derived from everyday actions and their outcomes (see Figure 1). In terms of self-related insight into idiosyncratic values and expectancies, this meta knowledge can be used to proactively prevent selfincongruent decisions that require much volitional, effortful control processes, or to recalibrate one's goal system when individuals get stuck in unsatisfying goal pursuits.

Effective action requires both skill and will. Questions of "will" are the domain of motivation theories. Questions of "skill” are the domain of knowledge acquisition theories, for example. My basic idea is that skill and will develop cyclically by engaging in natural actions that result in certain outcomes (e.g., success or failure, see Figure 1). For example, a child may be interested in engaging with a new toy, andto the extent that it can effectively manipulate the toy—-this sequence will feed back to initial will and skill parameters. That is, the child may be even more interested in the toy, and may have developed new skills. Or it may be not interested in the toy anymore because the interaction was either too difficult (leading to frustration) or too easy (leading to boredom). These cyclical processes happen more or less automatically. However, with growing meta-cognitive awareness, the individual may also learn something about one's motivation and capabilities from earlier engagements, which enables more systematic goal pursuits and less trial and error. This, in turn, should result in a better congruence between the expectations of the individual (e.g., how gratifying it will be to engage in an action, how well he or she can handle the problem) and the actual experiences and outcomes of the specific action. To the extent that such meta-knowledge is acquired and tapped in everyday goal pursuits, we can then speak about self-regulation.

With regard to motivational processes, self-regulation would, for example, mean that individuals get to know something about their personal values and preferences, and how they fit with their current action plans, as well as to external expectations and demands, and-based on this insight-repeatedly and deliberately decide what to do. This may lead either to goal maintenance or goal disengagement (cf., Brandstätter \& Schüler, 2013). 
With regard to capabilities, self-regulation would, for example, mean that individuals come to know something about learning strategies and their applicability to a certain task-related problem (given prior knowledge), and, based on this insight, repeatedly and deliberately decide how to proceed (cf., Leopold \& Leutner, 2015).

That is, from this perspective, self-regulation refers to deliberate decisions on what to do and how to do it; and these decisions are based on meta-cognitive insight. The more comprehensive this insight, the better individuals should be able to maximize their interests. Hence, fostering meta-cognitive insight would be a key process for helping individuals to enlarge their opportunities.

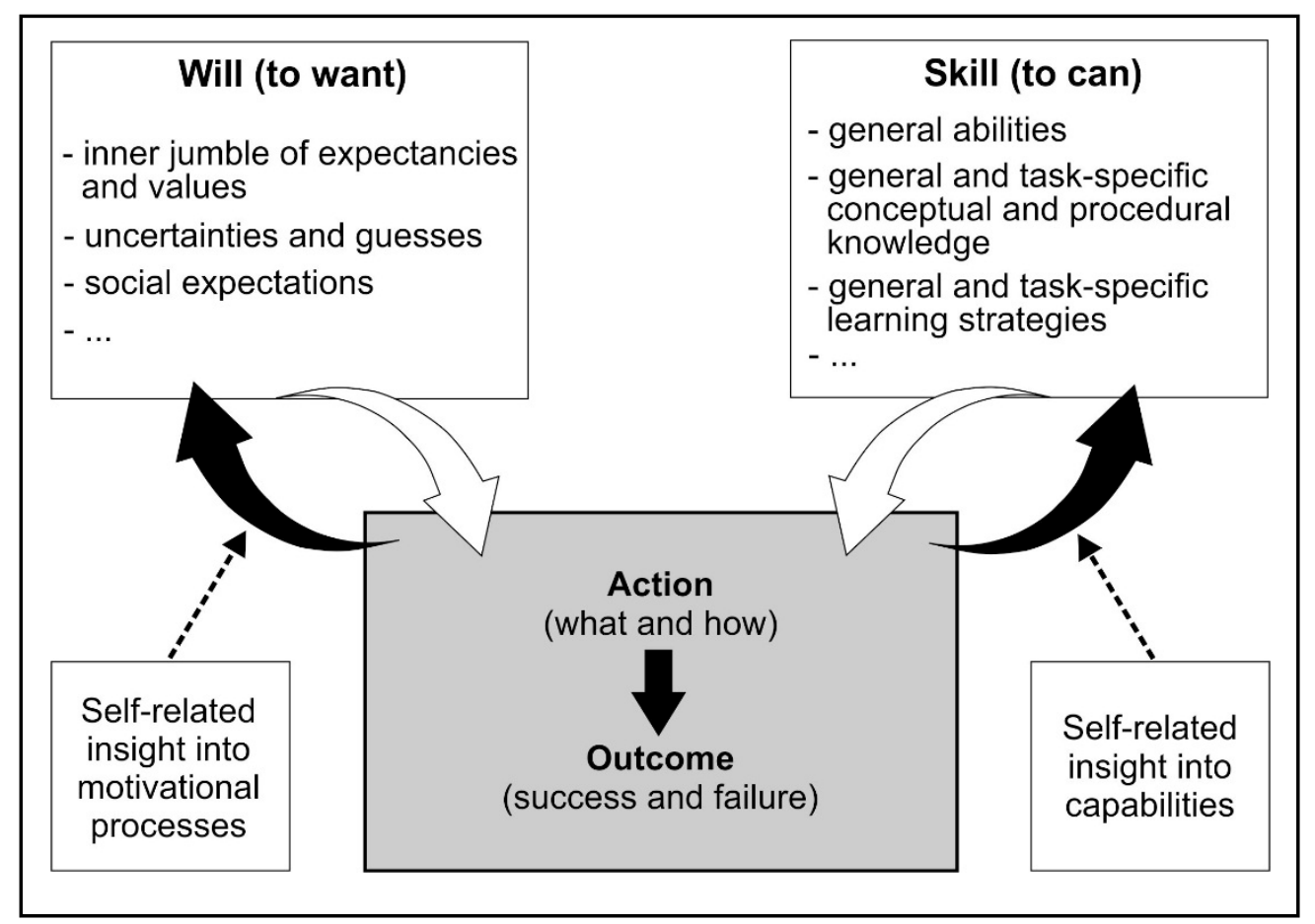

Figure 1. A model of self-regulation through meta-knowledge

This perspective of self-regulation as the acquisition and application of meta-cognitive knowledge about skill and will is quite different from a perspective that emphasizes volitional control processes. Take the following example: There is a stone to lift; its weight is $50 \mathrm{~kg}$. When a very small person wants to lift the stone, it may be too heavy. Hence, even though the person may be motivated enough to lift the stone, he or she may lack (physical) capabilities to accomplish the problem. How can self-regulation help in this situation? Obviously, it would not suffice to "pull oneself together" or to advise oneself to concentrate more on the details of the problem. Hence, self-regulation as effortful control processes would not change anything about the person's capabilities. Rather, to solve the problem, the person needs to realize that his or her present skills are insufficient for the specific task, and either needs to refrain from the wish to lift the stone, or needs to think about external assistance. These are meta-cognitive monitoring processes.

What about if the person possesses enough physical strength to lift the stone, but does not want to do so at the present moment? How can self-regulation help in this situation? Obviously, the current inner state of affairs in expectancies and values is not calibrated for this problem. Either the person does not think that he or she is capable of lifting the stone (although he or she actually may be), or he or she sees no (or not 
enough) value in lifting the stone. Again, volitional control processes would not change anything about the person's current motivation. What may help is to take one step back and see the situation from a different (broader) perspective, or to gain more (accurate) information about the problem. Then, the person may realize that his or her initial capability appraisal was wrong, and/or that lifting the stone may be instrumental for some other means (e.g., to help a colleague or to please a supervisor). To the extent that the new capability information is authentic in the eyes of the person, and/or the new means has authentic incentive potential for the person, the motivational parameters may change so that the person is now ready to lift the stone. Again, self-regulation here refers to meta-cognitive monitoring processes that result in an actual change in the motivational parameters, and not to control processes that override or suppress existing "problematic" motivational tendencies by other, more "suitable" motivational tendencies.

Referring back to the different concepts of the present habilitation project, the first perspective mirrors the mindfulness approach to self-regulation, whereas the second perspective reflects the self-control approach to self-regulation. In a mindful state, one is especially receptive to informational feedback, which, in principle, enables one to cherish positive intrinsic qualities of engagement, but also to tolerate momentary negative experiences (Arch \& Craske, 2006; Shapiro et al., 2006), so long as one has realized that these experiences are helpful for attaining a valuable end. Self-control, in its original sense (e.g., Tangney et al., 2004), refers to unconditionally blindfolding oneself with regard to the intrinsic qualities of engagement in favor of long-term goal pursuit. The feedback loop between the ends that individuals strive for and the experiential information that can be derived from current engagement is interrupted, which carries the risk of alienation (Kuhl \& Beckmann, 1994).

An important advantage of a meta knowledge perspective of self-regulation is that skill (e.g., intelligence, conceptual and procedural knowledge, learning strategies) and will (e.g., values, expectancies) can be distinguished as objects of awareness from the monitoring process itself. With regard to the will domain, this independence becomes difficult with regard to volitional control processes. It is important to note that automatic feedback loops, although possibly highly functional (Rheinberg \& Engeser, 2018; Sokolowski, 1997) from this perspective, would not be considered as self-regulation because no deliberate monitoring processes may be required. I acknowledge, however, that from a humanistic perspective, only such automatic processes emanating from the "true”, integrated self may be regarded as self-regulation in a narrow sense (e.g., Sheldon, 2014). However, given that such a congruence does not seem to naturally exist in many individuals (McClelland et al., 1989; Spangler, 1992; Thrash et al., 2007), there is a great potential for thinking about how individuals can be enabled to actively change something about this situation. 


\subsection{Improving meta-knowledge about one’s will}

In the current habilitation project, I focused on the relation between motivation and self-regulation in terms of monitoring - that is, the left part of Figure 1. Capability issues are only considered in as much as they reflect expectancy appraisals of an individual, thereby serving as a determinant of motivation. I took this focus because I believe that many issues typically regarded as self-regulatory failure or strength (e.g., procrastination) are, in fact, an issue of a lack of meta-cognitive insight into motivational processes, resulting in a conflict-prone motivational fundament of behavior. Consequently, it would require interventions that foster such meta-cognitive insight to help individuals attain their goals, rather than to train them to be persistent at any cost, for example. A crucial challenge in this regard is the inner jumble of different expectancies and values, uncertainties and guesses, and social expectations that determine current motivation (see Figure 1). Were we always clear and certain of what we want and what we like, and how gratifying it would be to follow and achieve a certain goal, issues of self-regulation would only regard the skill domain. However, as it stands, this lucidity seems quite difficult to achieve.

Despite the prevailing uncertainties that are inherent in predictions about what will be, two important barriers seem to hamper self-knowledge, thereby posing a threat to self-congruent goal pursuits. According to Carlson (2013), informational barriers refer to the quantity and quality of information that individuals have about themselves. For example, it seems especially challenging to know something about our implicit affectbased preferences, such as needs and motives (McClelland et al., 1989; Weinberger \& McClelland, 1990), and to consider these energetic motivational processes when setting goals. Consequently, we may rely too much on our explicit motivational self-concept, which could also be inaccurate. Fostering motivational competencies, such as those described by Rheinberg and Engeser (2010; 2012), seems facilitative for gaining increasingly adequate information about our affective preferences and how they fit upcoming situations. Motivational barriers refer to ego-protective motives (e.g., self-enhancement and self-verification), which lead to a bias in the processing of self-relevant information (Carlson, 2013), often resulting in inaccurate selfperceptions. For example, ego-threatening information is processed more superficially than is self-enhancing information (Green, Sedikides, \& Gregg, 2008). According to Carlson (2013), a mindful stance toward inner and outer reality should address both barriers to self-knowledge simultaneously, which she sees as critical to achieving a more accurate self-related insight. From this perspective, the development of motivational competencies should be facilitated by mindfulness because mindfulness enables a more comprehensive and accurate perception (i.e., quantity and quality of information) from a third-person perspective (i.e., detached from the ego).

There is ample evidence showing that students can be trained to develop meta knowledge with regard to the skill domain, and apply it independently from external regulation (e.g., Boekaerts, 1997; Collins, Brown, \& Newman, 1989; Leopold \& Leutner, 2015; Leutner, Leopold, \& den Elzen-Rump, 2007; Palincsar \& Brown, 1984; Pressley, Woloshyn, Lysynchuk, Martin, Wood, \& Willougyby, 1990; Souvignier \& Mokhlesgerami, 2006). However, with regard to the will domain, the situation seems more complex. The major reason why I think that reasoning and findings from the skill domain cannot be easily transferred to the will domain is that motivation has both cognitive and affective components, whereas the latter is crucial 
for the energetization of behavior (cf., Thrash \& Elliot, 2001). It should be difficult to alter these implicit energetic processes by means of "rational” instruction or modelling. For example, although it seems quite plausible that students can adopt reading strategies modeled by their teachers or competent peers (Rosenshine \& Meister, 1994; Spörer \& Schünemann, 2014), it seems unlikely that students adopt as easily values concerning the desirability of a learning task, or school and achievement goals in general. Simply telling a student that school is important (e.g., for career), math is not threatening, or physics is interesting is unlikely to result in a true change in the affective reactions to the specific object at hand. Even more critical, if affective preferences run counter to a specific goal pursuit, serious problems may arise when such a mismatch becomes chronic (Kehr, 2004; Kuhl \& Beckmann, 1994). Therefore, motivational changes require individuals to notice actual changes in their affective reactions toward a certain action.

Following this analysis, I see four main implications for the development of interventions aiming at building meta knowledge about idiosyncratic motivational processes. First, such interventions seem promising when they concentrate on the acquisition and application of meta knowledge about the motivational foundations of experience and performance that regard cognitive aspects of motivations in the first place. In principle, this means that classic motivational interventions that focus on expectancy and control beliefs (cf., Lazowski \& Hulleman, 2016) could be seen to foster self-regulation to the degree that they help students to acquire motivational meta knowledge, such as knowledge about adaptive attributional patterns following success and failure (Weiner, 2005). I think we can be prudently optimistic that students can have insight into such processes, and therefore, in principle, should be able to detect maladaptive patterns in a given situation independently from external regulation (e.g., psychologists and teachers), and—based on this analysis-develop a different (cognitive) perspective to their initial reasoning, thereby fostering experience and performance.

Second, in as much as motivational problems regard mainly the affective basis of experience and performance, meta knowledge may regard idiosyncratic likes and dislikes, as well as general internal and external factors, which influence the desirability of a goal, which is in line with the idea of motivational competence (Rheinberg \& Engeser, 2010; 2012; Roch et al., 2017). Based on this knowledge, individuals could be enabled to select situations and goals that fit their implicit, deeper personality structure in terms of needs and motives (Brunstein, 2018; Sheldon, 2014; Thrash \& Elliot, 2002). However, in order to circumvent biases due to ego-protective motives in this process, a general mindful stance should facilitate the acquisition of such self-relevant knowledge. It should be clear, however, that such value clarification interventions (Carlson, 2013) may eventually result in "painful” consequences, such as abandoning a certain goal, and therefore run counter to the idea of effortful goal maintenance at any cost.

Third, given that skill and will components are likely to interact with one another (e.g., one likes that which one is good at), intervention programs may combine exercises that address meta knowledge on skill and will issues. For example, it seems plausible that an understanding of the motivational principles of realistic goal setting, in conjunction with internal, variable attributions, can more easily be developed when applied to the acquisition of a specific learning strategy or skill (cf., Fries, Lund, \& Rheinberg, 1999; Souvignier \& Mokhlesgerami, 2006). 
I Synopsis: Chapter 5. Self-Regulation as Acquisition and Application of Meta Knowledge

Fourth, and finally, it is likely that meta knowledge about skill and will becomes applicable without external regulation only when sufficiently applied to idiosyncratic, real-life issues. Therefore, interventions should explicitly prepare and support such transfers. 


\subsection{Conclusion}

Taken together, the present habilitation project converges to the following major implications:

1. Situations of motivational conflicts seem crucial to understanding the difficulties that individuals face in educational contexts (e.g., students, teachers). As the present research is grounded in general ideas of motivation and self-regulation, it seems plausible that the present findings can be transferred to other contexts as well. Future research should also address the question of how incongruence with regard to one action tendency transfers to intrapsychic conflict between two action tendencies.

2. The notion of self-control is ambiguous because the relation of the proposed "capabilities" to basic processes of motivational (in-) congruence is typically not regarded. Future studies should address this question by controlling relevant motivational variables that regard the direction, and especially the energetization, of goals. In addition, research on self-control and procrastination seems to share a certain implicit normative ideology about how individuals "should” behave in order to act "rational” (e.g., waiting for the cookie, cf., Kohn, 2008), thereby neglecting that not all individuals value, like, and want the same things. In this regard, it seems a fruitful future research endeavor to explore the attributional consequences of explaining failure and success in goal pursuit in terms of motivational and volitional regulation processes, whereby perceptions of controllability and responsibility may play crucial roles (Weiner, 2005).

3. The concept of mindfulness offers a promising and fresh perspective to research on self-regulation and educational psychology. Complementary to the notion of self-control, it seems to me the more convincing concept when it comes to enabling individuals to expand their opportunities by means of meta knowledge. The facilitation of a third-person perspective that promotes comprehensive and receptive insight into internal processes, and their relation to external processes, seems to be a major function in this regard. However, to pin down the exact processes, it would be essential to assess within-person changes in mindfulness and related self-regulatory concepts, such as motivational conflicts over time and in natural contexts. In addition, more research is needed to investigate the relevance of mindfulness with regard to more tangible learning processes (i.e., elaboration, knowledge acquisition).

4. Research on self-regulation should profit from a shift to early processes of goal selection, complementary to subsequent volitional processes, such as planning and goal shielding. This would also imply investigating processes of self maintenance in complement to processes of goal maintenance (Kuhl \& Fuhrmann, 1998). Furthermore, it seems critical for future research to differentiate between motivational problems (which was the focus of the present habilitation project) and capability problems (cf., Sokolowski, 1997), and the relation between the two. With regard to the latter problem, an active and deliberate top-down intervention seems helpful, but may not always be required, for example, when in a state of flow (Rheinberg \& Engeser, 2018). With regard to motivational problems, the notion of self-regulation as volitional control seems much more complex, and potentially even detrimental for well-being (Kehr, 2004; Kuhl \& Beckmann, 1994). Therefore, motivational competencies that enable motive- and need-congruent goal pursuit seem especially desirable, and a mindful stance toward one's likes and dislikes may facilitate the development of such competencies. 


\section{References}

Achtziger, A., \& Gollwitzer, P. M. (2018). Motivation and volition in the course of action. In J. Heckhausen \& H. Heckhausen (Eds.), Motivation and action (3nd ed., pp. 485-527). Berlin, Germany: Springer.

Arch, J. J., \& Craske, M. G. (2006). Mechanisms of mindfulness: Emotion regulation following a focused breathing induction. Behaviour Research and Therapy, 44, 1849-1858.

Amstad, F. T., Meier, L. L., Fasel, U., Elfering, A., \& Semmer, N. K. (2011). A meta-analysis of workfamily conflict and various outcomes with a special emphasis on cross-domain versus matchingdomain relations. Journal of Occupational Health Psychology, 16, 151-169.

Baer, R. A. (2003). Mindfulness training as a clinical intervention: A conceptual and empirical review. Clinical Psychology: Science and Practice, 10, 125-143. doi:10.1093/clipsy/bpg015.

Baer, R. A., Smith, G. T., \& Allen, K. B. (2004). Assessment of mindfulness by self-report: The Kentucky Inventory of Mindfulness Skills. Assessment, 11, 191-206. doi:10.1177/1073191104268029

Baker, R., \& Siryk, B. (1999). Student Adaptation to College Questionnaire (SACQ) manual. Los Angeles, CA: Western Psychological Services.

Bargh, J. A., Gollwitzer, P. M., Lee-Chai, A., Barndollar, K., \& Troetschel, R. (2001). The automated will: Nonconscious activation and pursuit of behavioral goals. Journal of Personality and Social Psychology, 81, 1014-1027.

Barnes, S., Brown, K. W., Krusemark, E., Campbell, W. K., \& Rogge, R. D. (2007). The role of mindfulness in romantic relationship satisfaction and responses to relationship stress. Journal of Marital and Family Therapy, 33, 482-500. doi:10.1111/j.1752-0606.2007.00033.x

Baumeister, R. F., Gailliot, M., DeWall, C. N., \& Oaten, M. (2006). Self-regulation and personality: How interventions increase regulatory success, and how depletion moderates the effects of traits on behavior. Journal of Personality, 74, 1773-1801. https://doi.org/10.1111/j.1467-6494.2006.00428.x

Baumeister, R. F., \& Heatherton, T. F. (1996). Self-regulation failure: An overview. Psychological Inquiry, 7, 1-15. doi:10.1207/s15327965pli0701_1

Baumeister, R. F., Heatherton, T. F., \& Tice, D. M. (1994). Losing control: How and why people fail at selfregulation. San Diego: Academic Press.

Bembenutty, H., \& Karabenick, S. A. (2004). Inherent association between academic delay of gratification, future time perspective, and self-regulated learning. Educational Psychology Review, 16, 35-57. doi:10.1023/B:EDPR.0000012344.34008.5c

Berkowitz, L. (1996). Too sweeping and too narrow? Psychological Inquiry, 7, 25-28. https://doi.org/10.1207/s15327965pli0701_4

Bishop, S. R., Lau, M., Shapiro, S., Carlson, L., Anderson, N. D., Carmody, J., Segal, Z. V., Abbey, S., Speca, M., Velting, D., \& Devins, G. (2004). Mindfulness: A proposed operational definition. Clinical Psychology: Science and Practice, 11, 230-241. doi:10.1093/clipsy.bph077

Boekaerts, M. (1997). Self-regulated learning: A new concept embraced by researchers, policy makers, educators, teachers, and students. Learning and Instruction, 7, 161-186. 
Boekaerts, M., \& Niemivirta, M. (2000). Self-regulated learning: Finding a balance between learning goals and ego-protective goals. In M. Boekaerts, P.R. Pintrich, \& M. Zeidner (Eds.), Handbook of selfregulation (pp. 417-451). San Diego, CA: Academic Press.

Boudreaux, M. J., \& Ozer, D. J. (2013). Goal conflict, goal striving, and psychological well-being. Motivation and Emotion, 37, 433-443. doi: 10.1007/s11031-012-9333-2

Bowlin, S. L., \& Baer, R. A. (2012). Relationships between mindfulness, self-control, and psychological functioning. Personality and Individual Differences, 52, 411-415. doi:10.1016/j.paid.2011.10.050

Brandstätter, V., \& Schüler, J. (2013). Action crisis and cost-benefit thinking: A cognitive analysis of a goaldisengagement phase. Journal of Experimental Social Psychology, 49, 543-553. http://dx.doi.org/10.1016/j.jesp.2012.10.004

Brown, K. W., \& Ryan, R. M. (2003). The benefits of being present: Mindfulness and its role in psychological well-being. Journal of Personality and Social Psychology, 84, 822-848. doi:10.1037/00223514.84.4.822

Brown, K. W., Ryan, R. M., \& Creswell, J. D. (2007). Mindfulness: Theoretical foundations and evidence for its salutary effects. Psychological Inquiry, 18, 211-237. doi:10.1080/10478400701598298

Brunstein, J. C. (2018). Implicit and explicit motives. In J. Heckhausen \& H. Heckhausen (Eds.), Motivation and action (3nd ed., pp. 369-405). Berlin, Germany: Springer.

Brunstein, J. C., Schultheiss, O. C., \& Grässmann, R. (1998). Personal goals and emotional well-being: The moderating role of motive dispositions. Journal of Personality and Social Psychology, 75, 494-508.

Carlson, E. N. (2013). Overcoming the barriers to self-knowledge: Mindfulness as a path to seeing yourself as you really are. Perspectives on Psychological Science, 8, 173-186. https://doi.org/10.1177/1745691612462584

Carroll, J., Perkowitz, W., Lurigio, A., \& Weaver, K. (1987). Sentencing goals, causal attributions, and personality. Journal of Personality and Social Psychology, 52, 107-118.

Carter, E. C., Kofler, L. M., Forster, D. E., \& McCullough, M. E. (2015). A series of meta-analytic tests of the depletion effect: Self-control does not seem to rely on a limited resource. Journal of Experimental Psychology: General, 144, 796-815. https://doi.org/10.1037/xge0000083

Carver, C. S., \& White, T. L. (1994). Behavioral inhibition, behavioral activation, and affective responses to impending reward and punishment: The BIS/BAS scales. Journal of Personality and Social Psychology, 67, 319-333. doi:10.1037/0022-3514.67.2.319

Collins, A., Brown, J.S., \& Newman, S.E. (1989). Cognitive apprenticeship: Teaching the crafts of reading, writing, and mathematics. In L.B. Resnick (Ed.), Knowing, learning, and instruction: Essays in honor of Robert Glaser (pp. 453-494). Hillsdale, NJ: Lawrence Erlbaum.

Covington, M. V. (2000). Goal theory, motivation, and school achievement: An integrative review. Annual Review of Psychology, 51, 171-200. https://doi.org/10.1146/annurev.psych.51.1.171

Crandall, C. S. (1994). Prejudice against fat people: Ideology and self-interest. Journal of Personality and Social Psychology, 66, 882-894. 
Deci, E. L., \& Ryan, R. M. (2000). The "what" and the "why" of goal pursuits: Human needs and the selfdetermination of behavior. Psychological Inquiry, 11, 227-268. doi:10.1207/S15327965PLI1104_01

de Ridder, D. T. D., \& Gillebaart, M. (2017). Lessons learned from trait self-control in well-being: Making the case for routines and initiation as important components of trait self-control. Health Psychology Review, 11, 89-99. doi:10.1080/17437199.2016.1266275

de Ridder, D., Lensvelt-Mulders, G., Finkenauer, C. F., Stok, M., \& Baumeister, R. F. (2012). Taking stock of self-control: A meta-analysis of how trait self-control relates to a wide range of behaviors. Personality and Social Psychology Review, 16, 76-99. doi:10.1016/j.paid.2011.01.015

Diehl, M., Semegon, A. B., \& Schwarzer, R. (2006). Assessing attention control in goal pursuit: a component of dispositional self-regulation. Journal of Personality Assessment, 86, 306-317. http://dx.doi.org/10.1207/s15327752jpa8603_06

Duckworth, A. L., Gendler, T. S., \& Gross, J. J. (2016): Situational strategies for self-control. Perspectives on Psychological Science, 11, 35-55. DOI: 10.1177/1745691615623247.

Duckworth, A. L., \& Seligman, M. E. P. (2005). Self-discipline outdoes IQ in predicting academic performance of adolescents. Psychological Science, 16, 939-944. doi:10.1111/j.14679280.2005.01641.x.

Duckworth, A. L., \& Seligman, M. E. P. (2006). Self-discipline gives girls the edge: Gender in self-discipline, grades, and achievement test scores. Journal of Educational Psychology, 98, 198-208. https://doi.org/10.1037/0022-0663.98.1.198

Eccles, J. S., \& Wigfield, A. (1995). In the mind of the actor: The structure of adolescents' achievement task values and expectancy-related beliefs. Personality and Social Psychology Bulletin, 21, 215-225. doi:10.1177/0146167295213003

Eccles, J. S., \& Wigfield, A. (2002). Motivational beliefs, values, and goals. Annual Review of Psychology, 53, 109-132. doi:10.1146/annurev.psych.53.100901.135153

Eckert, M., Ebert, D. D., Lehr, D., Sieland, B., \& Berking, M. (2016). Overcome procrastination: Enhancing emotion regulation skills reduce procrastination. Learning and Individual Differences, 52, 10-18. https://doi.org/10.1016/j.lindif.2016.10.001

Emmons, R. A., \& King, L. A. (1988). Conflict among personal strivings: Immediate and long-term implications for psychological and physical wellbeing. Journal of Personality and Social Psychology, 54, 1040-1048. doi: 10.1037/0022-3514.54.6.1040

Enzmann, D., \& Kleiber, D. (1989). MBI/EK: Maslach Burnout Inventory - deutsche Fassung. PSYNDEX Tests Info [MBI - German version]. Heidelberg, Germany: Asanger.

Fetterman, A. K., Robinson, M. D., Ode, S., \& Gordon, K. H. (2010). Neuroticism as a risk factor for behavioral dysregulation: A mindfulness-mediation perspective. Journal of Social and Clinical Psychology, 29, 301-321. doi:10.1521/jscp.2010.29.3.301

Fishbach, A., \& Shah, J. Y. (2006). Self-control in action: Implicit dispositions toward goals and away from temptations. Journal of Personality and Social Psychology, 90, 820-832. 
Flake, J. K., Barron, K. E., Hulleman, C., McCoach, B. D., \& Welsh, M. E. (2015). Measuring cost: The forgotten component of expectancy-value theory. Contemporary Educational Psychology, 41, 232244. https://doi.org/10.1016/j.cedpsych.2015.03.002

Fries, S., \& Dietz, F. (2007). Learning in the face of temptation: The case of motivational interference. Journal of Experimental Education, 76, 93-112.

Fries, S., Dietz, F. \& Schmid, S. (2008). Motivational interference in learning: The impact of leisure alternatives on subsequent self-regulation. Contemporary Educational Psychology, 33, 119-133.

Fries, S., Lund, B. \& Rheinberg, F. (1999). Läßt sich durch gleichzeitige Motivförderung das Training des induktiven Denkens optimieren [Does simultaneous motive modification optimise the teaching of inductive reasoning]? Zeitschrift für Pädagogische Psychologie, 13, 37-49. doi: 10.1024//10100652.13.12.37.

Fries, S., \& Schmid, S. (2007). Lernen bei attraktiven Handlungsalternativen [Learning with attractive alternatives: The phenomenon of motivational interference]. Zeitschrift für Pädagogische Psychologie, 21, 271-281. https://doi.org/10.1024/1010-0652.21.3.271

Fries, S., Schmid, S., Dietz, F. \& Hofer, M. (2005). Conflicting values and their impact on learning. European Journal of Psychology of Education, 20, 259-273.

Friese, M., \& Hofmann, W. (2016). State mindfulness, self-regulation, and emotional experience in everyday life. Motivation Science, 2, 1-14. https://doi.org/10.1037/mot0000027

Friese, M., Messner, C., \& Schaffner, Y. (2012). Mindfulness meditation counteracts self-control depletion. Consciousness and Cognition, 21, 1016-1022. doi:10.1016/j.concog.2012.01.008.

Frone, M. R., Russell, M., \& Cooper, M. L. (1992). Antecedents and outcomes of work-family conflict: Testing a model of the work-family interface. Journal of Applied Psychology, 77, 65-78.

Fujita, K. (2011). On conceptualizing self-control as more than the effortful inhibition of impulses. Personality and Social Psychology Review, 15, 352-366. https://doi.org/10.1177/1088868311411165

Gollwitzer, P. M. (1990). Action phases and mind-sets. In E. T. Higgins, \& R. M. Sorrentino (Eds.), Handbook of motivation and cognition (Vol. 2, pp. 53-92). New York: Guilford Press.

Gorges, J., \& Grund, A. (2017). Aiming at a Moving Target: Theoretical and Methodological Considerations in the Study of Intraindividual Goal Conflict between Personal Goals. Frontiers in Psychology, 8, 2011. https://doi.org/10.3389/fpsyg.2017.02011

Gray, J. S., Ozer, D. J., \& Rosenthal, R. (2017). Goal conflict and psychological well-being: A meta-analysis. Journal of Research in Personality, 66, 27-37. doi: 10.1016/j.jrp.2016.12.003

Green, J. D., Sedikides, C., \& Gregg, A. P. (2008). Forgotten but not gone: The recall and recognition of selfthreatening memories. Journal of Experimental Social Psychology, 44, 547-561. doi:10.1016/j.jesp.2007.10.006

Greenhaus, J. H., \& Beutell, N. J. (1985). Sources of conflict between work and family roles. Academy of Management Review, 10, 76-88. 
Grund, A. (2013). Motivational profiles in study-leisure conflicts: Both quality and quantity matters. Learning and Individual Differences, 26, 201-211. doi: http://dx.doi.org/10.1016/j.lindif.2013.01.009

Grund, A., Brassler, N. K., \& Fries, S. (2014). Torn between study and leisure: How motivational conflicts relate to students' academic and social adaptation. Journal of Educational Psychology, 106, 242 257. doi:10.1037/a0034400

Grund, A., Brassler, N. K., \& Fries, S. (2016). The long arm of work: A motivational conflict perspective on teacher strain. Teaching and Teacher Education, 60, 153-163. doi: http://dx.doi.org/10.1016/j.tate.2016.08.013

Grund, A., \& Carstens, C. (2019). Self-control motivationally reconsidered: “Acting” self-controlled is different from "being good" at self-control. Motivation and Emotion, 43, 63-81. doi: 10.1007/s11031018-9721-3

Grund, A., \& Fries, S. (2012). Motivational interference in study-leisure conflicts: How opportunity costs affect the self-regulation of university students. Educational Psychology, 32, 589-612. doi:10.1080/01443410.2012.674005

Grund, A., \& Fries, S. (2014). Study and leisure interference as mediators between students' self-control capacities and their domain-specific functioning and general well-being. Learning and Instruction, 31, 23-32. doi:10.1016/j.learninstruc.2013.12.005

Grund, A., Grunschel, C., Bruhn, D., \& Fries, S. (2015). Torn between want and should: An experiencesampling study on motivational conflict, well-being, self-control, and mindfulness. Motivation and Emotion, 39, 506-520. doi:10.1007/s11031-015-9476-z.

Grund, A., Schmid, S. \& Fries, S. (2015). Studying against your will: Motivational interference in action. Contemporary Educational Psychology, 41, 209-217. doi: 10.1016/j.cedpsych.2015.03.003

Grund, A., \& Senker, K. (2018). Motivational foundations of self-control and mindfulness and their role in study-leisure conflicts. Learning and Individual Differences, 68, 72-84. doi:10.1016/j.lindif.2018.10.007

Grunschel, C., Schwinger, M., Steinmayr, R., \& Fries, S. (2016). Effects of using motivational regulation strategies on students' academic procrastination, academic performance, and well-being. Learning and Individual Differences, 49, 162-170. https://doi.org/10.1016/j.lindif.2016.06.008

Hagemann, W., \& Geuenich, K. (2009). Burnout-Screening-Skalen (BOSS): Manual [Burnout screening scales: Manual]. Göttingen, Germany: Hogrefe.

Hagger, M. S., Wood, C., Stiff, C., \& Chatzisarantis, N. L. (2010). Ego depletion and the strength model of self-control: A meta-analysis. Psychological Bulletin, 136, 495-525. http://dx.doi.org/10.1037/a0019486

Heckhausen, H., \& Gollwitzer, P.M. (1987). Thought contents and cognitive functioning in motivational vs. volitional states of mind. Motivation and Emotion, 11, 101-120. doi:10.1007/BF00992338.

Hidi, S., \& Renninger, K. A. (2006). The Four-Phase Model of Interest Development. Educational Psychologist, 41, 111-127. doi:10.1207/s15326985ep4102_4 
Hofer, M. (2010). Adolescents' development of individual interests: A product of multiple goal regulation? Educational Psychologist, 45, 149-166. doi:10.1080/00461520.2010.493469

Hofer, M., Kuhnle, C., \& Kilian, B. (2014). Erfolg in der Schule und andere Entwicklungsaufgaben: Tätigkeiten von Jugendlichen im Wettstreit (Success in school and other developmental tasks: Rivalry between adolescents activities). Unterrichtswissenschaft, 42, 171-186. Doi:10.3262/UW1402171

Hofer, M., Kuhnle, C., Kilian, B., Marta, E., \& Fries, S. (2011). Motivational interference in school-leisure conflict and learning outcomes: The differential effects of two value conceptions. Learning and Instruction, 21, 301-316. doi:10.1016/j.learninstruc.2010.02.009

Hofer, M., Schmid, S., Fries, S., Dietz, F., Clausen, M., \& Reinders, H. (2007). Individual values, motivational conflicts, and learning for school. Learning and Instruction, 17, 17-28. doi:10.1016/j.learninstruc.2006.11.003

Hofmann, W., Baumeister, R. F., Förster, G., \& Vohs, K. D. (2012). Everyday temptations: An experience sampling study on desire, conflict, and self-control. Journal of Personality and Social Psychology, 102, 1318-1335. doi: 10.1037/a0026545.

Hofmann, W., Luhmann, M., Fisher, R., Vohs, K. D., \& Baumeister, R. F. (2014). Yes, but are they happy? Effects of trait self-control on affective well-being and life satisfaction. Journal of Personality, 82, 265-277. doi:10.1111/jopy.12050

Howell, A. J., \& Buro, K. (2011). Relations among mindfulness, achievement-related self-regulation, and achievement emotions. Journal of Happiness Studies, 12, 1007-1022. https://doi.org/10.1007/s10902-010-9241-7

Howell, A. J., \& Watson, D. C. (2007). Procrastination: Associations with achievement goal orientation and learning strategies. Personality and Individual Differences, 43, 167-178.

Inglehart, R. (1997). Modernization and postmodernization. Princeton, NJ: Princeton University Press.

Inzlicht, M., Bartholow, B. D., \& Hirsh, J. B. (2015): Emotional foundations of cognitive control. Trends in Cognitive Sciences, 19, 126-132. DOI: 10.1016/j.tics.2015.01.004.

Inzlicht, M., \& Schmeichel, B. J. (2012). What is ego depletion? Toward a mechanistic revision of the resource model of self-control. Psychological Science, 7, 450 - 463.

Job, V., \& Brandstätter, V. (2009). Get a taste of your goals: Promoting motive-goal congruence through affect-focus goal fantasy. Journal of Personality, 77, 1527-1559. https://doi.org/10.1111/j.14676494.2009.00591.x

Job, V., Dweck, C., \& Walton, G. (2010). Ego depletion: Is it all in your head? Implicit theories about willpower affect self-regulation. Psychological Science, 21, 1686-1693. doi:10.1177/0956797610384745

Kabat-Zinn, J. (2003). Mindfulness-based interventions in context: Past, present, and future. Clinical Psychology: Science and Practice, 10, 144-156. doi:10.1093/clipsy.bpg016

Kappes, H. B., Schwörer, B., \& Oettingen, G. (2012). Needs instigate positive fantasies of idealized futures. European Journal of Social Psychology, 42, 299-307. https://doi.org/10.1002/ejsp.1854

Katz, D., \& Kahn, R. L. (1978). The social psychology of organizations. NewYork: Wiley. 
Kehr, H. M. (2004). Implicit/explicit motive discrepancies and volitional depletion among managers. Personality and Social Psychology Bulletin, 30, 315-327. https://doi.org/10.1177/0146167203256967

Kilian, B., Hofer, M., Fries, S., \& Kuhnle, C. (2010). The conflict between on-task and off-task actions in the classroom and its consequences for motivation and achievement. European Journal of Psychology of Education, 25, 67-85.

Kilian, B., Hofer, M., \& Kuhnle, C. (2010). Value orientations as determinants and outcomes of conflicts between on-task and off-task actions in the classroom. Learning and Individual Differences, 20, 501506.

Klingsieck, K. B. (2013). Procrastination: When good things don't come to those who wait. European Psychologist, 18, 24-34. https://doi.org/10.1027/1016-9040/a000138

Kohn, A. (2008, November). Why self-discipline is overrated. Phi Delta Kappan, 90, 168-176. Retrieved from http://www.alfiekohn.org/

Koranyi, N., \& Rothermund, K. (2012). When the grass on the other side of the fence doesn't matter: Reciprocal romantic interest neutralizes attentional bias towards attractive alternatives. Journal of Experimental Social Psychology, 48, 186-191. doi: 10.1016/j.jesp.2011.06.012

Kotabe, H. P., \& Hofmann, W. (2015). On integrating the components of self-control. Perspectives on Psychological Science, 10, 618-638. https://doi.org/10.1177/1745691615593382

Kuhl, J. (1996). Who controls whom when "I control myself"? Psychological Inquiry, 7, 61-68. https://doi.org/10.1207/s15327965pli0701_12

Kuhl, J., \& Beckmann, J. (1994). Alienation: Ignoring one’s preferences. In J. Kuhl \& J. Beckmann (Eds.), Volition and personality: Action versus state orientation (pp. 375-390). Göttingen, Germany: Hogrefe.

Kuhl, J., \& Fuhrmann, A. (1998). Decomposing self-regulation and self-control: The volitional components checklist. In J. Heckhausen \& C. Dweck (Eds.), Life span perspectives on motivation and control (pp. 15-49). Mahwah, NJ: Erlbaum.

Kuhnle, C., Hofer, M., \& Kilian, B. (2010). The relationship of value orientations, self-control, frequency of school-leisure conflicts, and life-balance in adolescence. Learning and Individual Differences, 20, 251-255. doi:10.1016/j.lindif.2010.02.003

Lakey, C. E., Campbell, W. K., Brown, K. W., \& Goodie, A. S. (2007). Dispositional mindfulness as a predictor of the severity of gambling outcomes. Personality and Individual Differences, 43, 16981710. doi:10.1016/j.paid.2007.05.007

Langer, E. J. (2000). Mindful learning. Current Directions in Psychological Science, 9, 220-223. doi:10.1111/1467-8721.00099

Lazowski, R. A., \& Hulleman, C. S. (2016). Motivation Interventions in Education. Review of Educational Research, 86, 602-640. https://doi.org/10.3102/0034654315617832

Leopold, C., \& Leutner, D. (2015). Improving students' science text comprehension through metacognitive self-regulation when applying learning strategies. Metacognition and Learning, 10, 313-346. https://doi.org/10.1007/s11409-014-9130-2 
Leutner, D., Leopold, C., \& den Elzen-Rump, V. (2007). Self-regulated learning with a text-highlighting strategy. Zeitschrift für Psychologie/Journal of Psychology, 215, 174-182. https://doi.org/10.1027/0044-3409.215.3.174

Linnenbrink-Garcia, L., Durik, A. M., Conley, A. M., Barron, K. E., Tauer, J. M., Karabenick, S. A., \& Harackiewicz, J. M. (2010). Measuring situational interest in academic domains. Educational and Psychological Measurement, 70, 647-671. doi:10.1177/0013164409355699

Liu, Q.-Q., Zhou, Z.-K., Yang, X.-J., Kong, F.-C., Sun, X.-J., \& Fan, C.-Y. (2018). Mindfulness and sleep quality in adolescents: Analysis of rumination as a mediator and self-control as a moderator. Personality and Individual Differences, 122, 171-176. https://doi.org/10.1016/j.paid.2017.10.031

Louro, M. J., Pieters, R., \& Zeelenberg, M. (2007). Dynamics of multiple-goal pursuit. Journal of Personality and Social Psychology, 93, 174-193. https://doi.org/10.1037/0022-3514.93.2.174

Luszczynska, A., Diehl, M., Gutiérrez-Doña, B., Kuusinen, P., \& Schwarzer, R. (2004). Measuring one component of dispositional self-regulation: Attention control in goal pursuit. Personality and Individual Differences, 37, 555-566.

McClelland, D. C., Koestner, R., \& Weinberger, J. (1989). How do self-attributed and implicit motives differ? Psychological Review, 96, 690-702.

Meijman, T. F., \& Mulder, G. (1998). Psychological aspects of workload. In P. J. Drenth, H. Thierry, \& C. J. de Wolff (Eds.), Handbook of work and organizational psychology (2nd ed., pp. 5-33). Hove, UK: Psychology Press

Mesmer-Magnus, J. R., \& Viswesvaran, C. (2005). Convergence between measures of work-to-family and family-to-work conflict: A meta-analytic examination. Journal of Vocational Behavior, 67, 215-232.

Muraven, M., Tice, D. M., \& Baumeister, R. F. (1998). Self-control as a limited resource: Regulatory depletion patterns. Journal of Personality and Social Psychology, 74, 774-789. doi:10.1037/00223514.74.3.774.

Netemeyer, R. G., Boles, J. S., \& McMurrian, R. (1996). Development and validation of work-family conflict and family-work conflict scales. Journal of Applied Psychology, 81, 400-410.

Nohe, C., \& Sonntag, K. (2014). Work-family conflict, social support, and turnover intentions: A longitudinal study. Journal of Vocational Behavior, 85, 1-12.

Oettingen, G., \& Stephens, E. J. (2009). Fantasies and motivationally intelligent goal setting. In G. B. Moskowitz \& H. Grant (Eds.), The psychology of goals (pp. 153-178). New York: Guilford Press.

Palincsar, A.S., \& Brown, A.L. (1984). Reciprocal teaching of comprehension fostering and monitoring activities. Cognition and Instruction, 1, 117-175.

Paulhus, D. L. (1994). Balanced Inventory of Desirable Responding: Reference manual for BIDR version 6. Unpublished manuscript, University of British Columbia, Vancouver, Canada.

Pellegrini, R. J., Queirolo, S. S., Monarrez, V. E., \& Valenzuela, D. M. (1997). Political identification and perceptions of homelessness: Attributed causality and attitudes on public policy. Psychological Reports, 80, 1139-1148. 
Philipp, A., \& Kunter, M. (2013). How do teachers spend their time? A study on teachers' strategies of selection, optimisation, and compensation over their career cycle. Teaching and Teacher Education, $35,1-12$.

Pintrich, P. (2000). The role of goal orientation in self-regulated learning. In M. Boekaerts, P. Pintrich, \& M. Zeidner (Eds.), Handbook of self-regulation (pp. 452-502). San Diego, CA: Academic.

Pressley, M., Woloshyn, V., Lysynchuk, L.M., Martin, V., Wood, E., \& Willougyby, T. (1990). A primer of research on cognitive strategy instruction: The important issues and how to address them. Educational Psychology Review, 2, 1-58.

Rebetez, M. M. L., Rochat, L., Barsics, C., \& van der Linden, M. (2016). Procrastination as a self-regulation failure: The role of inhibition, negative affect, and gender. Personality and Individual Differences, 101, 435-439. https://doi.org/10.1016/j.paid.2016.06.049

Rheinberg, F., \& Engeser, S. (2010). Motive training and motivational competence. In O. C. Schultheiss \& J. C. Brunstein (Eds.), Implicit Motives (pp. 510-548). Oxford: University Press.

Rheinberg, F., \& Engeser, S. (2012). Motivational competence: The joint effect of implicit and explicit motives on self-regulation and flow experience. In D. Leontiev (Ed.). Motivation, consciousness and self-regulation (pp. 79-89). New York: Nova Science Publishers.

Rheinberg, F., \& Engeser, S. (2018). Intrinsic motivation and flow. In J. Heckhausen \& H. Heckhausen (Eds.). Motivation and action (3rd ed., pp. 579-622). Berlin, Germany: Springer.

Riediger, M. (2007). Interference and facilitation among personal goals: Age-group differences and associations with well-being and behavior. In B. R. Little, K. Salmela-Aro, J.-E. Nurmi, \& S. D. Philipps (Eds.), Personal Project Pursuit: Goals, Action, and Human Flourishing (119-143). Mahwah, NJ: Erlbaum.

Riediger, M., \& Freund, A. M. (2004). Interference and facilitation among personal goals: Differential associations with subjective wellbeing and persistent goal pursuit. Personality and Social Psychology Bulletin, 30, 1511-1523. doi: 10.1177/0146167204271184

Riediger, M., \& Freund, A. M. (2008). Me against myself: Motivational conflicts and emotional development in adulthood. Psychology and Aging, 23, 479-494. doi:10.1037/a0013302

Roch, R. M., Rösch, A. G., \& Schultheiss, O. C. (2017). Enhancing congruence between implicit motives and explicit goal commitments: Results of a randomized controlled trial. Frontiers in Psychology, 8:1540. doi: 10.3389/fpsyg.2017.01540

Roeser, R. W., \& Peck, S. C. (2009). An education in awareness: Self, motivation, and self-regulated learning in contemplative perspective. Educational Psychologist, 44, 119-136. https://doi.org/10.1080/00461520902832376

Rosenshine, B., \& Meister, C. (2016). Reciprocal Teaching: A Review of the Research. Review of Educational Research, 64, 479-530. https://doi.org/10.3102/00346543064004479

Ryan, R. M., \& Deci, E. L. (2001). On happiness and human potentials: A review of research on hedonic and eudaimonic well-being. Annual Review of Psychology, 52, 141-166. doi:10.1146/annurev.psych.52.1.141 
Ryff, C. D. (1989). Happiness is everything, or is it? Explorations on the meaning of psychological wellbeing. Journal of Personality and Social Psychology, 57, 1069-1081. doi:10.1037/00223514.57.6.1069

Salomon, G., \& Globerson, T. (1987). Skill may not be enough: The role of mindfulness in learning and transfer. International Journal of Educational Research, 11, 623-637.

Sauer, S., Lynch, S., Walach, H., \& Kohls, N. (2011). Dialectics of mindfulness: Implications for western medicine. Philosophy, Ethics, and Humanities in Medicine, 6, 10. https://doi.org/10.1186/17475341-6-10

Saunders, B., Milyavskaya, M., Etz, A., Randles, D., \& Inzlicht, M. (2018). Reported self-control is not meaningfully associated with inhibition-related executive function: A Bayesian analysis. http://doi.org/10.17605/OSF.IO/BXFSU

Schallberger, U. (2005). Kurzskala zur Erfassung der positiven Aktivierung, negativen Aktivierung und Valenz in Experience Sampling Studien (PANAVA-KS) [Scales for assessing positive/negative activation and valence in experience sampling studies]. Research report. Retrieved March 2, 2013, from http://www.research-projects.uzh.ch/p6975.htm

Schmid, S., Hofer, M., Dietz, F., Reinders, H., \& Fries, S. (2005). Value orientations and action conflicts in students' everyday life: An interview study. European Journal of Psychology of Education, 20, 243257. doi:10.1007/BF03173555

Schouwenburg, H. C., \& Groenewoud, J. (2001). Study motivation under social temptation: Effects of trait procrastination. Personality and Individual Differences, 30, 229-240.

Schraw, G., Bruning, R., \& Svoboda, C. (1995). Sources of situational interest. Journal of Reading Behavior, $27,1-17$.

Schultheiss, O. C., Patalakh, M., Rawolle, M., Liening, S., \& MacInnes, J. J. (2011). Referential competence is associated with motivational congruence. Journal of Research in Personality, 45, 59-70. https://doi.org/10.1016/j.jrp.2010.11.014

Schultheiss, O. C., \& Brunstein, J. C. (1999). Goal imagery: Bridging the gap between implicit motives and explicit goals. Journal of Personality, 67, 1-38.

Schunk, D. (2001). Social-cognitive theory and self-regulated learning. In B. Zimmerman \& D. Schunk (Eds.), Self-regulated learning and academic achievement: Theoretical perspectives (2nd ed., pp. 125-151). Mahwah, NJ: Lawrence Erlbaum Associates, Inc.

Schwartz, S. H. (1992). Universals in the content of values: Theoretical advances and empirical tests in 20 countries. In M. Zanna (Ed.), Advances in experimental social psychology (Vol. 25, pp. 1-65). New York: Academic press.

Schwinger, M., Steinmayr, R., \& Spinath, B. (2009). How do motivational regulation strategies affect achievement: Mediated by effort management and moderated by intelligence. Learning and Individual Differences, 19, 621-627.

Shah, J. Y., Friedman, R., \& Kruglanski, A. W. (2002). Forgetting all else: On the antecedents and consequences of goal shielding. Journal of Personality and Social Psychology, 83, 1261-1280. 
Shah, J. Y., \& Kruglanski, A. W. (2002). Priming against your will: How accessible alternatives affect goal pursuit. Journal of Experimental Social Psychology, 38, 368-383. doi:10.1016/S00221031(02)00005-7

Shapiro, S. L., Carlson, L. E., Astin, J. A., \& Freedman, B. (2006). Mechanisms of mindfulness. Journal of Clinical Psychology, 62, 373-386. https://doi.org/10.1002/jclp.20237

Shapiro, S. L., Lyons, K. E., Miller, R. C., Butler, B., Vieten, C., \& Zelazo, P. D. (2015). Contemplation in the classroom: A new direction for improving childhood education. Educational Psychology Review, 27, 1-30. https://doi.org/10.1007/s10648-014-9265-3

Sheldon, K. M. (2014). Becoming oneself: The central role of self-concordant goal selection. Personality and Social Psychology Review, 18, 349-365. doi: 10.1177/1088868314538549

Sheldon, K. M., \& Elliot, A. J. (1998). Not all goals are personal goals: Comparing autonomous and controlled reasons for goals as predictors of effort and attainment. Personality and Social Psychology Bulletin, 24, 546-557. doi:10.1177/0146167298245010.

Sheldon, K. M., Prentice, M., \& Halusic, M. (2014). The experiential incompatibility of mindfulness and flow absorption. Social Psychological and Personality Science, 6, 276-283. https://doi.org/10.1177/1948550614555028

Skitka, L. J., Mullen, E., Griffin, T., Hutchinson, S., \& Chamberlin, B. (2002). Dispositions, scripts, or motivated correction? Understanding ideological differences in explanations for social problems. Journal of Personality and Social Psychology, 83, 470-487. https://doi.org/10.1037//00223514.83.2.470

Skitka, L. J., \& Tetlock, P. E. (1992). Allocating scarce resources: A contingency model of distributive justice. Journal of Experimental Social Psychology, 28, 33-37.

Sokolowski, K. (1997). Sequentielle und Imperative Konzepte des Willens [Sequential and imperative theories of volition]. Psychologische Beiträge, 39, 346-369.

Souvignier, E., \& Mokhlesgerami, J. (2006). Using self-regulation as a framework for implementing strategy instruction to foster reading comprehension. Learning and Instruction, 16, 57-71. https://doi.org/10.1016/j.learninstruc.2005.12.006

Spangler, W. D. (1992). Validity of questionnaire and TAT measures of need for achievement: Two metaanalyses. Psychological Bulletin, 112, 140-154.

Spörer, N., \& Schünemann, N. (2014). Improvements of self-regulation procedures for fifth graders' reading competence: Analyzing effects on reading comprehension, reading strategy performance, and motivation for reading. Learning and Instruction, 33, 147-157. https://doi.org/10.1016/j.learninstruc.2014.05.002

Steel, P. (2007). The nature of procrastination: A meta-analytic and theoretical review of quintessential selfregulatory failure. Psychological Bulletin, 133, 65-94. https://doi.org/10.1037/0033-2909.133.1.65

Strick, M., \& Papies, E. K. (2017). A brief mindfulness exercise promotes the correspondence between the implicit affiliation motive and goal setting. Personality and Social Psychology Bulletin, 43, 623637. https://doi.org/10.1177/0146167217693611 
Stroud, S. (2010). Is procrastination weakness of will? In C. Andreou \& M. D. White (Eds.), The thief of time: Philosophical essays on procrastination (pp. 51-67). Oxford: Oxford University Press.

Tangney, J. P., Baumeister, R. F., \& Boone, A. L. (2004). High self-control predicts good adjustment, less pathology, better grades, and interpersonal success. Journal of Personality, 72, 271-322. doi:10.1111/j.0022-3506.2004.00263.x

Tarantino, N., Lamis, D. A., Ballard, E. D., Masuda, A., \& Dvorak, R. D. (2015). Parent-child conflict and drug use in college women: A moderated mediation model of self-control and mindfulness. Journal of Counseling Psychology, 62, 303-13. doi:10.1037/cou0000013.

Teasdale, J. D. (1999). Emotional processing, three modes of mind and the prevention of relapse in depression. Behaviour Research and Therapy, 37, 53-77. doi:10.1016/S0005-7967(99)00050-9.

Thrash, T. M., \& Elliot, A. J. (2001). Delimiting and integrating achievement motive and goal constructs. In A. Efklides, J. Kuhl, \& R. M. Sorrentino (Eds.), Trends and prospects in motivation research (pp. 3-21). Boston: Kluwer.

Thrash, T. M., \& Elliot, A. J. (2002). Implicit and self-attributed achievement motives: Concordance and predictive validity. Journal of Personality, 70, 729-755.

Thrash, T. M., Elliot, A. J., \& Schultheiss, O. C. (2007). Methodological and dispositional predictors of congruence between implicit and explicit need for achievement. Personality and Social Psychology Bulletin, 33, 961-974. https://doi.org/10.1177/0146167207301018

Vollmeyer, R., \& Rheinberg, F. (2006). Motivational effects on self-regulated learning with different tasks. Educational Psychological Review, 18, 239-253. doi:10.1007/s10648-006-9017-0

Waters, L., Barsky, A., Ridd, A., \& Allen, K. (2015). Contemplative education: A systematic, evidencebased review of the effect of meditation interventions in schools. Educational Psychology Review, 27, 103-134. https://doi.org/10.1007/s10648-014-9258-2

Wentzel, K. R., \& Miele, D. B. (2016). Handbook of motivation at school. New York: Routledge Taylor \& Francis Group.

Weinberger, J., \& McClelland, D. C. (1990). Cognitive versus traditional motivational models? Irreconcilable or complementary? In E. T. Higgins \& R. M. Sorrentino (Eds), Handbook of motivation and cognition (Vol. 2, pp. 562-597). New York, NY: Guilford Press.

Weiner, B. (2005). Motivation from an attribution perspective and the social psychology of perceived competence. In Andrew J. Elliot, \& Carol S. Dweck (eds.), Handbook of Competence and Motivation (pp. 73-84). New York, NY: Guilford Press.

Weinert, F. (1987). Bildhafte Vorstellungen des Willens [Metaphoric conceptions of will]. In H. Heckhausen, P. M. Gollwitzer, \& F. Weinert (Eds.), Jenseits des Rubikon: Der Wille in den Humanwissenschaften (pp. 10-26). Berlin: Springer Verlag.

Westermann, R., Heise, E., Spies, K., \& Trautwein, U. (1996). Identifikation und Erfassung von Komponenten der Studienzufriedenheit [Identifying and assessing components of student satisfaction]. Psychologie in Erziehung und Unterricht, 43, 1-22.

Wolters, C. A. (2003). Regulation of motivation: Evaluating an underemphasized aspect of self-regulated learning. Educational Psychologist, 38, 189-205. https://doi.org/10.1037/0022-0663.95.1.179 
Wolters, C. A., Won, S., \& Hussain, M. (2017). Examining the relations of time management and procrastination within a model of self-regulated learning. Metacognition and Learning. Advanced online publication. https://doi.org/10.1007/s11409-017-9174-1

Yusainy, C., \& Lawrence, C. (2014). Relating mindfulness and aggression to harm to the self and to others. Personality and Individual Differences, 64, 78-83. doi:10.1016/j.paid.2014.02.015.

Yusainy, C., \& Lawrence, C. (2015). Brief mindfulness induction could reduce aggression after depletion. Consciousness and Cognition, 33, 125-134. doi:10.1016/j.concog.2014.12.008.

Zimmerman, B. J. (2000). Attaining self-regulation: A social-cognitive perspective. In M. Boekaerts, P. R. Pintrich, \& M. Zeidner (Eds.), Handbook of self-regulation (pp. 13-39). San Diego: Academic Press. 
II Appendix: Publications of the habilitation project 


\section{Publication List}

List of publications (Kumulus) for the schriftliche Habilitationsleistung.

\begin{tabular}{|c|c|c|}
\hline No. & Reference & $\begin{array}{l}\text { 5-years } \\
\text { IF (2018) } \\
\end{array}$ \\
\hline 1 & $\begin{array}{l}\text { Grund, A., Schmid, S. \& Fries, S. (2015). Studying against } \\
\text { your will: Motivational interference in action. } \\
\text { Contemporary Educational Psychology, 41, 209-217. } \\
\text { doi:10.1016/j.cedpsych.2015.03.003 }\end{array}$ & 4.08 \\
\hline 2 & $\begin{array}{l}\text { Grund, A., Brassler, N. K., \& Fries, S. (2016). The long } \\
\text { arm of work: A motivational conflict perspective on } \\
\text { teacher strain. Teaching and Teacher Education, } 60 \text {, 153- } \\
\text { 163. doi:10.1016/j.tate.2016.08.013 }\end{array}$ & 3.00 \\
\hline 3 & $\begin{array}{l}\text { Gorges, J., \& Grund, A. (2017). Aiming at a Moving } \\
\text { Target: Theoretical and Methodological Considerations in } \\
\text { the Study of Intraindividual Goal Conflict between } \\
\text { Personal Goals. Frontiers in Psychology, 8, } 2011 \text {. } \\
\text { doi:10.3389/fpsyg.2017.02011 }\end{array}$ & 2.82 \\
\hline 4 & $\begin{array}{l}\text { Grund, A., \& Fries, S. (2014). Study and leisure } \\
\text { interference as mediators between students' self-control } \\
\text { capacities and their domain-specific functioning and } \\
\text { general well-being. Learning and Instruction, 31, 23-32. } \\
\text { doi:10.1016/j.learninstruc.2013.12.005 }\end{array}$ & 4.62 \\
\hline 5 & $\begin{array}{l}\text { Grund, A., \& Carstens, C. (2019). Self-control } \\
\text { motivationally reconsidered: “Acting” self-controlled is } \\
\text { different from "being good" at self-control. Motivation and } \\
\text { Emotion, 121, 120-130. doi: 10.1016/j.paid.2017.09.03S }\end{array}$ & 2.46 \\
\hline 6 & $\begin{array}{l}\text { Grund, A., \& Senker, K. (2018). Motivational foundations } \\
\text { of self-control and mindfulness and their role in study- } \\
\text { leisure conflicts. Learning and Individual Differences, 68, } \\
\text { 72-84. doi:10.1016/j.lindif.2018.10.007 }\end{array}$ & 2.26 \\
\hline 7 & $\begin{array}{l}\text { Grund, A., Grunschel, C., Bruhn, D., \& Fries, S. (2015). } \\
\text { Torn between want and should: An experience-sampling } \\
\text { study on motivational conflict, well-being, self-control, } \\
\text { and mindfulness. Motivation and Emotion, 39, 506-520. } \\
\text { doi:10.1007/s11031-015-9476-z. }\end{array}$ & 2.46 \\
\hline 8 & $\begin{array}{l}\text { Grund, A., Schäfer, N., Sohlau, S., Uhlich, J., \& Schmid, } \\
\text { S. (2019). Mindfulness and situational interest. } \\
\text { Educational Psychology, 39, 353-369. doi: } \\
\text { 10.1080/01443410.2018.1553296 }\end{array}$ & 2.10 \\
\hline 9 & $\begin{array}{l}\text { Grund, A., \& Fries, S. (2018). Understanding } \\
\text { procrastination: A motivational approach. Personality and } \\
\text { Individual Differences, 121, 120-130. } \\
\text { doi:10.1016/j.paid.2017.09.03S }\end{array}$ & 2.40 \\
\hline 10 & $\begin{array}{l}\text { Grund, A., Fries, S., \& Rheinberg, F. (2018). Know your } \\
\text { preferences: Self-regulation as need-congruent goal- } \\
\text { selection. Review of General Psychology, 22, 437-451. } \\
\text { doi: 10.1037/gpr0000159 }\end{array}$ & 2.55 \\
\hline
\end{tabular}

